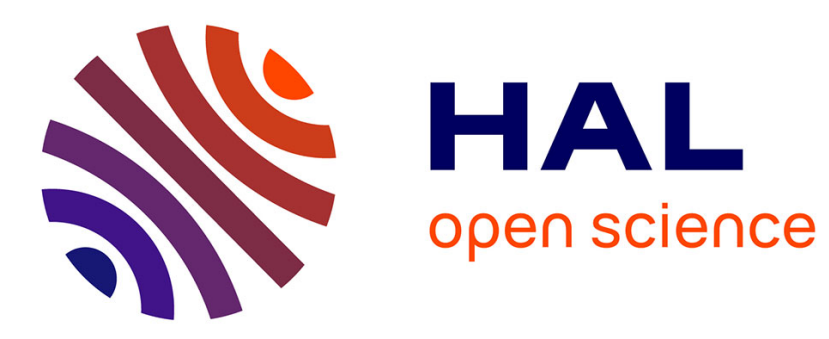

\title{
Synthetic Tomographic Images of Slabs from Mineral Physics
}

\author{
Yanick Ricard, Estelle Mattern, Jan Matas
}

\section{To cite this version:}

Yanick Ricard, Estelle Mattern, Jan Matas. Synthetic Tomographic Images of Slabs from Mineral Physics. Robert. D. van der Hilst, Jay. D. Bass, Jan Matas, Jeannot Trampert. Changing Views on the Structure, Composition, and Evolution of Earth's Deep, American Geophysical Union, Washington, DC, pp.285-302, 2005, Geophysical monograph series, Volume 160, AGU Code: GM1604254., 0-87590-425-4. hal-00093481

\section{HAL Id: hal-00093481 https://hal.science/hal-00093481}

Submitted on 13 Sep 2006

HAL is a multi-disciplinary open access archive for the deposit and dissemination of scientific research documents, whether they are published or not. The documents may come from teaching and research institutions in France or abroad, or from public or private research centers.
L'archive ouverte pluridisciplinaire HAL, est destinée au dépôt et à la diffusion de documents scientifiques de niveau recherche, publiés ou non, émanant des établissements d'enseignement et de recherche français ou étrangers, des laboratoires publics ou privés. 


\title{
Synthetic Tomographic Images of Slabs from Mineral Physics
}

\author{
Y. Ricard, E. Mattern and J. Matas \\ Laboratoire des Sciences de la Terre, UMR CNRS 5570, Lyon, France
}

\begin{abstract}
The mantle structures observed by seismic tomography can only be linked with convection models by assuming some relationships between temperature, density and velocity. These relationships are complex and non linear even if the whole mantle has a uniform composition. For example, the density variations are not only related to the depth dependent thermal expansivity and incompressibility, but also to the distribution of the mineralogical phases that are themselves evolving with temperature and pressure. In this paper, we present a stoichiometric iterative method to compute the equilibrium mineralogy of mantle assemblages by Gibbs energy minimization. The numerical code can handle arbitrary elemental composition in the system $\mathrm{MgO}, \mathrm{FeO}, \mathrm{CaO}, \mathrm{Al}_{2} \mathrm{O}_{3}$ and $\mathrm{SiO}_{2}$ and reaches the thermodynamic equilibrium by choosing the abundances of 31 minerals belonging to 14 possible phases. The code can deal with complex chemical activities for minerals belonging to solid state solutions. We illustrate our approach by computing the phase diagrams of various compositions with geodynamical interest (pyrolite, harzburgite and oceanic basalt). Our simulations are in reasonable agreement with high pressure and high temperature experiments. We predict that subducted oceanic crust remains significantly denser than normal mantle even near the core mantle boundary. We then provide synthetic tomographic models of slabs. We show that properties computed at thermodynamic equilibrium are significantly different from those computed at fixed mineralogy. We quantify the three potential contributions of the seismic anomalies (intrinsic thermal effect, changes in mineralogy induced by temperature variations, changes in the bulk composition) and show that they are of comparable magnitudes. Although the accuracy of our results is limited by the uncertainties on the thermodynamic parameters and equations of states of each individual mineral, future geodynamical models will need to include these mineralogical aspects to interpret the tomographic results as well as to explain the geochemical observations.
\end{abstract}

\section{Tomographic images of slabs}

For the last 20 years the observation by seismic tomography of the large scale structure of the mantle has provided a fantastic tool to test, sometimes to contradict but often to confirm, the findings of geodynamical studies. It has also pointed to the necessity to go beyond simple qualitative agreements and have a closer look to mineralogical data that links temperature or density (the usual parameters of convective models) to velocity anomalies.

The general agreement on convection of fluids heated largely by internal radioactivity is that the regions of lithospheric downwellings (the subduction zones) should be underlaid by cold descending plumes (the slabs). These structures should dominate the mantle heterogeneity structure whereas hot ascending plumes (presumably the hot-spots) should have a less important role [Davies and Richards,
1992; Bercovici et al., 2000]. Indeed, the slab flow must extract the radioactive heat production plus the mantle and core secular cooling while the hot spot flow only carries the core cooling [Davies, 1988].

This view results in a testable consequence that the presentday mantle structure should, at first order, be the result of past subductions [Richards and Engebretson, 1992]. Starting from a compilation of plate reconstruction models spanning the last 200 Myrs [Lithgow-Bertelloni et al., 1993], Ricard et al. [1993] compute the position that subducted slabs could have in the mantle. Their very simple model assume that each piece of slab sinks vertically and that the slab excess density is conserved through the whole mantle.

The quality of this geodynamical model based on paleoplate reconstructions, lies in its robustness. Indeed there is basically no adjustable parameters; the density of the lithosphere at subduction is well known (i.e., Turcotte and Schu- 


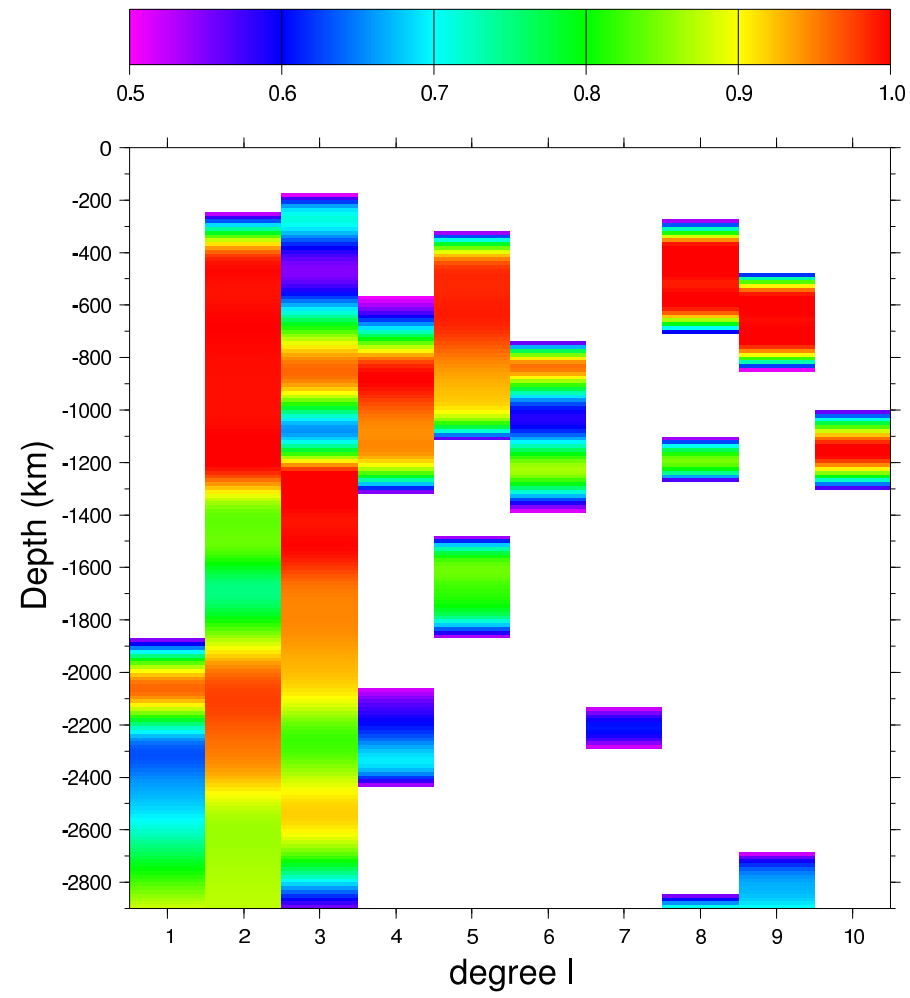

Figure 1. Comparison between a geodynamical model of Cenozoic and Mesozoic slab subduction and a tomographic model. The color panel represents, as a function of depth and harmonic degree, the significance level of the correlation between a slab model [Ricard et al., 1993] and a synthetic tomographic Smean model (Becker and Boschi, 2002). Only significance levels larger than 0.5 are depicted.

bert [1982]) and the vertical velocity reduction at $650 \mathrm{~km}$ depth is easy to estimate. As large scale geoid modeling suggests a viscosity increase by a factor $30-100$ at $650 \mathrm{~km}$ depth, average mantle velocity should be decreased in the lower mantle by a factor 3-5 [Richards, 1991].

The resulting density model provides a remarkable fit to the Earth's gravity field [Ricard et al., 1993]. It also compares favorably to tomographic models as can be illustrated with the synthetic S model ("Smean model" of Becker and Boschi [2002]), which is a weighted average of previously published models [Grand et al., 1997; Ritsema and van Heijst, 2000; Masters et al., 200]. The results are similar when other tomographic models are used but we hope that the synthetic Smean model emphasizes the common structures found by various tomographic approaches .

Figure 1 depicts the significance levels of the correlations between the slab and the tomographic models (this statistical quantity is an objective measure of the meaningfulness of the correlations). The horizontal axis is the spherical harmonic degree $l$ of the heterogeneity (the inverse wavelength is $\sim 20000 / l$ in $\mathrm{km}$ ). The vertical axis is depth. Only significance levels larger than $50 \%$ are plotted (i.e., when there is more than $50 \%$ of chance that the correlation is meaningful, the red colors indicate that the correlations are meaningful at $90 \%$ level ). At degrees 2 and 3 there is a very good correlation between the subduction and the tomographic models. At higher degrees, the correlations are restricted to the upper half of the mantle but the upper-lower mantle transition is not associated with a significant decrease of these correlations. To precisely compute the correlations at high degree in the deep lower mantle would require a knowledge of the positions and velocities of Mesozoic subductions that we do not have.

The reader may or may not consider this plot to be a convincing indication that sinking slabs are the major ingredient of mantle anomalies. Taking into account the uncertainties of seismic topography and even more the extreme simplicity of the geodynamical model (neglecting heat diffusion, slab lateral advection, the necessary existence of hot plumes...) this first order correlation seems to confirm the fact that tomographic models are in agreement with geodynamical models based on mostly internally heated fluid dynamics, i.e. with a mantle dynamics dominated by cold plumes.

This overall correlation between seismic models and geodynamical models has also been discussed on a more regional scales (e.g., [van der Voo et al., 1999]). These correlations, however, do not address the problem of the respective amplitudes of density and velocity anomalies. They do not even indicate that the observed velocity anomalies are of thermal rather than petrological origins.

In Figure 2, we depict a tomographic $\mathrm{P}$ wave model across Japan [Karason and van der Hilst, 2000]. In the top of Figure 2, this model has been plotted using the same color scale as in Fukao et al. [1992]. The bottom panel of Figure 2 represents the exact same data set but with the color scale of Bijwaard and Spakman [2000]. Basically along the same great circle, these authors have published, with their own models, very similar results which indicate the good general agreement between models. Although Figure 2 may suggest slab penetrations, with significant thickening/deformation in the lower mantle in agreement with geodynamical models, the very significant decrease in the lower mantle must be explained. This can only be done after a closer look to temperature/velocity/density relationships and therefore to mineralogy. Otherwise the interpretation of tomographic images in term of non-penetration or straight penetration is affected by the non-objective choice of the color scale as illustrated in Figure 2.

In this paper we discuss the amplitudes of the density and velocity anomalies that may be expected for a sinking slab. To do this exercise, we first discuss the possible mineralogical composition at depth of a realistic slab, then the relationships between these mineralogical compositions and the associated thermal and chemical anomalies. We only address the direct problem, i.e. we discuss how the mineral physics can be used to predict realistic seismic anomalies. We analyze and evaluate the importance of the three fundamental contributions to lateral variations; thermal, miner- 

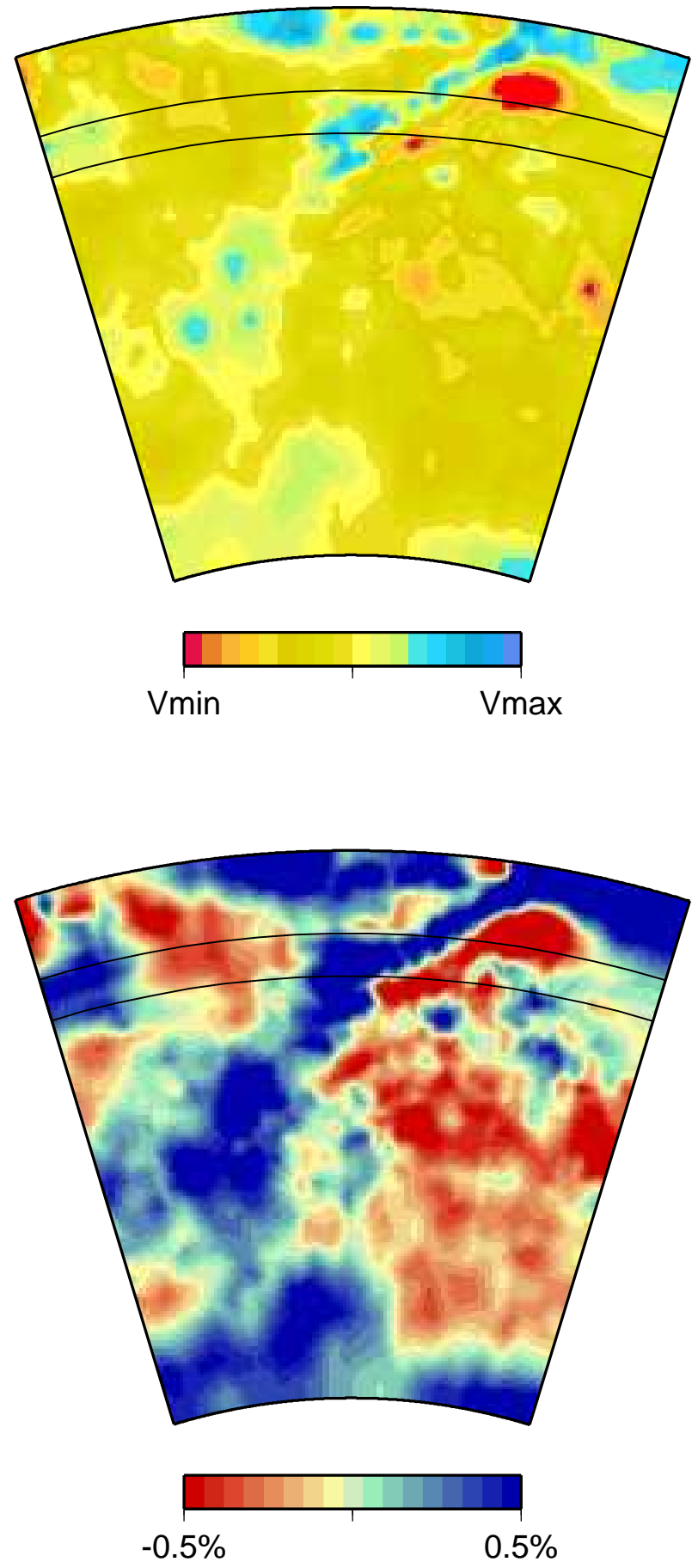

Figure 2. Tomographic cross sections across Japan through the P-wave tomographic model of Karason and van der Hilst [2000]. The top map uses the same color scale as Fukao et al. [1992]. It may suggest a stagnant slab lying on the upper-lower mantle interface (top). Using a color scale that saturates [Bijwaard and Spakman, 2000], the bottom map favors the interpretation of easy slab penetration. alogical and petrological. We do not attempt to formulate the more complex inverse problem and do not try interpret any specific tomographic model in terms of temperature and compositional variations.

\section{Mineralogical Composition of the Mantle}

The total elemental composition of the Earth can be estimated form geochemical considerations (e.g., Hart and Zindler [1989]). The direct natural samples (ophiolites, orogenic peridotites, xenoliths) only represent the uppermost mantle (first $200 \mathrm{~km}$ ). There are no samples of the lower mantle, the only information on its composition and structure comes from analyzes of propagation of seismic waves and of other geophysical observables (free oscillations, geoid modelling...). The mineralogical composition of the deeper mantle is thus obtained by indirect methods. Knowing the elastic properties of different minerals, it is indeed possible to test the compatibility of various bulk compositions and temperature profiles with various seismic and geophysical observations. An inverse problem can then be formulated to derive the most probable composition by fitting the seismic radial model (e.g. Mattern et al. [2005]) or the tomographic lateral variations (e.g. Trampert et al. [2004]). The elastic properties of each mantle minerals and the possible mineralogical assemblages that need to be considered, can be approached by different ways:

-experimental in-situ observations of high-pressure and high-temperature assemblages,

-purely theoretical ab initio computations,

-equilibrium thermodynamic computations based on single mineral properties either obtained from observations (e.g., calorimetry, Raman and Brillouin spectroscopy, high$\mathrm{P}$ and high-T X-ray diffraction) or from theoretical models (e.g., vibrational approach, ab initio calculations).

Each method has some advantages and some limitations. Purely experimental works are providing the most important informations. However for practical reasons, they are limited to relatively simple mineralogical assemblages. Some of the major high-pressure mantle phases are not quenchable (e.g., $\mathrm{CaSiO}_{3}$-perovskite) and the simultaneous HP-HT in situ analysis are still technically very difficult. The control of the sample oxidation state as well as the P-T conditions, is also another difficulty.

The ab initio calculation (i.e. directly solving a quantum mechanics problem) is very powerful since a precise control of pressure, temperature and oxidation conditions associated with the numerical experiment, is possible. The approach is however limited by various approximations needed to implement the quantum theory and by the computational cost necessary for the simulation of realistic mantle assemblages. It is usually used for single minerals and for a limited number of binary solid solutions (e.g., Bukowinski and Akber, [2005], this volume), this volume).

The classical thermodynamic modeling stands in between 
the two previous methods. It combines fundamental thermodynamics (first and second principles) with accurate experimental observations of single mineral physical properties. It considers that the convecting Earth's mantle is locally in thermodynamic equilibrium. The proportions of minerals can therefore be calculated by a free-energy minimization technique and the global mantle properties are then obtained using the single mineral properties weighted by mineral proportions.

The assumption of thermodynamic equilibrium is questionable at least in the coldest part of subducting slabs [Kirby et al., 1996]. A complete kinetic modeling of the mantle mineralogy is presently out of reach. Only a few kinetic reactions (e.g., between forsterite and $\mathrm{Mg}$-Wadsleyite) are reasonably well documented for a numerical modeling [Kerschhofer et al., 2000; Mosenfelder et al., 2000]. We are aware of the possible limitations of the thermodynamic approach that we use.

Over the past few decades several methods and techniques of equilibrium phase calculations have been proposed. In the early seventies, Barron [1968] has designed a computer program (GAPMIS) to determine phase equilibria in binary and ternary silicate systems. This code was designed to deal with complex non-ideal solid solutions in order to model various immiscibility gaps. It was however restricted to ambient pressure. The phase equilibrium calculations have been largely developed for low pressure igneous petrology. These studies were started by Bottinga and Richet [1978], Ghiorso and Carmichael [1980], Berman and Brown [1985]. A sophisticated computer code MELTS calculating phase equilibrium in silicate liquid systems was fine-tuned by Ghiorso in the nineties (see Ghiorso [1997], for a review).

The thermodynamic modeling of solid silicate systems under high pressures (i.e., at depths exceeding $300 \mathrm{~km}$ ) has been developed by Saxena and Eriksson [1983], Wood and Holloway [1984] and Bina and Wood [1986]. The first studies were limited to rather simple systems aiming essentially to study details of the $410-\mathrm{km}$ discontinuity. The computations in the $\mathrm{MgO}-\mathrm{FeO}-\mathrm{SiO}_{2}$ multicomponent system were further extended by works by Wood [1987], Kuskov and Panferov [1991], Fabrichnaya and Kuskov [1991], Saxena et al. [1993], Saxena [1996].

Ita and Stixrude [1992] have considered realistic mantle compositions including $\mathrm{CaO}$ and $\mathrm{Al}_{2} \mathrm{O}_{3}$ components. However, the phase determination was discussed separately for the olivine and the residual pyroxene-garnet parts. Their phase diagrams were in reasonable agreement with experimental studies. However, having two separated subsystems prevent from modeling the details of $410-\mathrm{km}$ and $660-\mathrm{km}$ discontinuity. The interaction between olivine polymorphs, garnet and pyroxene around the depth of $410 \mathrm{~km}$ was carefully studied by Stixrude [1997] by analytical computational methods. The only complete free-energy minimization code for mantle like mineralogies was presented by Sobolev and Babeyko [1994].
The phase diagrams by Ita and Stixrude [1992] have been used in various later studies (e.g. Vacher et al. [1998], Goes et al. [2004]) as the baseline for the interpretation of observed lateral seismic anomalies. Such approach does not necessarily ensure the condition of thermodynamic equilibrium.

\section{Gibbs minimization}

\subsection{Basic concepts}

The Earth mantle mineralogical system can be represented by a collection of $K$ simple oxides. We take into consideration $\mathrm{MgO}, \mathrm{FeO}, \mathrm{CaO}, \mathrm{Al}_{2} \mathrm{O}_{3}, \mathrm{SiO}_{2}$ labeled by the indices $k$, from 1 to $K=5$. These five oxides allows us to describe $99 \mathrm{wt} \%$ of a peridotitic composition and about $95 \mathrm{wt} \%$ of an oceanic crust composition. Our mineralogical system does not include alcalins $(\mathrm{Na}, \mathrm{K}, \ldots)$, various transition metals, $(\mathrm{Ti}, \mathrm{Cr}, \mathrm{Ni}, \ldots)$, ferric iron, hydrous phases, carbonates, metallic alloys, for which a complete set of thermodynamic parameters is unavailable. These elements can however be introduced for more specific studies [Matas et al., 2000a, b; Fiquet et al., 2002]. The oxides are distributed into $J$ possible phases consisting in solid state solutions of $I$ simple minerals also called end-members. In this paper we consider $I=29$ minerals belonging to $J=13$ phases (see Table 1).

Complex phases can include up to 5 simple end-members. The magnesium (index $k=1$ ), with molar abundance $b_{M g}=b_{1}$, is present in 11 different minerals, for example in forsterite, $\mathrm{Mg}_{2} \mathrm{SiO}_{4}$, an end-member with index $i$, belonging to the phase $\phi(i)$, olivine, $(\mathrm{Mg}, \mathrm{Fe})_{2} \mathrm{SiO}_{4}$. An end-member $i$, with molar abundance $n_{i}$, contains $s_{i k}$ moles of the oxide $k$ (e.g., $\mathrm{Mg}_{2} \mathrm{SiO}_{4}$ contains $s_{i 1}=2$ moles of $\mathrm{MgO}$ ). We call $S$ the matrix with coefficients $s_{i k}$ of the linear operator that relates the end-member abundance (a space of dimension $I$ ) to the elemental abundances (a space of dimension $K$ ). Total elemental conservation simply writes

$$
\sum_{i=1}^{I} s_{i k} n_{i}=b_{k},
$$

where, of course, the molar abundances are positive

$$
n_{i} \geq 0 \quad \forall i \in 1 . . I .
$$

The choice of minerals and phases shown in Table 1 is the result of a compromise between introducing the largest possible number of mantle minerals and avoiding minerals with too poorly known thermo-chemical parameters. This choice does not allow us to reproduce all minor complexities of the mantle mineralogy. For example, our choice of mineral species cannot account for the incorporation small proportions of $\mathrm{Al}$ in stishovite or $\mathrm{CaSiO}_{3}$ perovskite, contrary to what is experimentally observed (e.g., Ono et al. [2001]; Takafuji et al. [2002]). In the absence of a complete set of parameters (i.e. the equation of state and a complete set of calorimetric parameters) the perovskite to post-perovskite 
Table 1. Mineralogical phases and their end-members. Each line gives the name and the crystallographic formula of an independent phase. The names and chemical formulae of the end-members that can be present in a given phase are shown after parenthesis.

\begin{tabular}{lcc}
\hline Olivine $(\alpha)$ & Forsterite & $\mathrm{Mg}_{2} \mathrm{SiO}_{4}$ \\
$(\mathrm{Mg}, \mathrm{Fe})_{2} \mathrm{SiO}_{4}$ & Fayalite & $\mathrm{Fe}_{2} \mathrm{SiO}_{4}$ \\
\hline Olivine $(\beta)$ & Mg-Wadsleyite & $\mathrm{Mg}_{2} \mathrm{SiO}_{4}$ \\
$(\mathrm{Mg}, \mathrm{Fe})_{2} \mathrm{SiO}_{4}$ & Fe-Wadsleyite & $\mathrm{Fe}_{2} \mathrm{SiO}_{4}$ \\
\hline Ringwoodite $(\gamma)$ & Mg-Ringwoodite & $\mathrm{Mg}_{2} \mathrm{SiO}_{4}$ \\
$(\mathrm{Mg}, \mathrm{Fe})_{2} \mathrm{SiO}_{4}$ & Fe-Rinwooditeite & $\mathrm{Fe}_{2} \mathrm{SiO}_{4}$ \\
\hline Magnesiowustite & Periclase & $\mathrm{MgO}$ \\
$(\mathrm{Mg}, \mathrm{Fe}) \mathrm{O}$ & Wustite & $\mathrm{FeO}$ \\
\hline Perovskite & Mg-Perovskite & $\mathrm{MgSiO}_{3}$ \\
$(\mathrm{Mg}, \mathrm{Fe}, \mathrm{Al})$ & Fe-Perovskite & $\mathrm{FeSiO}_{3}$ \\
$(\mathrm{Al}, \mathrm{Si}) \mathrm{O}_{3}$ & Al-Perovskite & $\mathrm{Al}_{2} \mathrm{O}_{3}$ \\
\hline $\mathrm{Akimotoite}$ & $\mathrm{Mg}$-Akimotoite & $\mathrm{MgSiO}_{3}$ \\
$(\mathrm{Mg}, \mathrm{Fe}) \mathrm{SiO}{ }_{3}$ & Fe-Akimotoite & $\mathrm{FeSiO}_{3}$ \\
\hline Orthopyroxene & Orthoenstatite & $\mathrm{MgSiO}_{3}$ \\
$(\mathrm{Mg}, \mathrm{Fe}) \mathrm{SiO} \mathrm{S}_{3}$ & Orthoferrosilite & $\mathrm{FeSiO}_{3}$ \\
\hline $\mathrm{Clinopyroxene}$ & Diopside & $\mathrm{CaMgSi}_{2} \mathrm{O}_{6}$ \\
$(\mathrm{Ca}, \mathrm{Mg}, \mathrm{Fe})$ & Hedenbergite & $\mathrm{CaFeSi}_{2} \mathrm{O}_{6}$ \\
$(\mathrm{Mg}, \mathrm{Fe}, \mathrm{Al})$ & Ca-Tschermak & $\mathrm{CaAl}_{2} \mathrm{SiO}_{6}$ \\
$(\mathrm{Al}, \mathrm{Si})_{2} \mathrm{O}_{6}$ & Clinoenstatite & $\mathrm{Mg}_{2} \mathrm{Si}_{2} \mathrm{O}_{6}$ \\
& Clinoferrosilite & $\mathrm{Fe}_{2} \mathrm{Si}_{2} \mathrm{O}_{6}$ \\
\hline $\mathrm{Grenat}$ & Pyrope & $\mathrm{Mg}_{3} \mathrm{Al}_{2} \mathrm{Si}_{3} \mathrm{O}_{12}$ \\
$(\mathrm{Ca}, \mathrm{Mg}, \mathrm{Fe})_{3}$ & Almandin & $\mathrm{Fe}_{3} \mathrm{Al}_{2} \mathrm{Si}_{3} \mathrm{O}_{12}$ \\
$(\mathrm{Mg}, \mathrm{Fe}, \mathrm{Al}, \mathrm{Si})_{2}$ & Grossulaire & $\mathrm{Ca}_{3} \mathrm{Al}_{2} \mathrm{Si}_{3} \mathrm{O}_{12}$ \\
$\mathrm{Si} \mathrm{O}_{12}$ & Mg-Majorite & $\mathrm{Mg}_{4} \mathrm{Si}_{4} \mathrm{O}_{12}$ \\
& Fe-Majorite & $\mathrm{Fe}_{4} \mathrm{Si}_{4} \mathrm{O}_{12}$ \\
\hline $\mathrm{Al}-\varphi$ & Corundum & $\mathrm{Al}_{2} \mathrm{O}_{3}$ \\
\hline Coesite & Coesite & $\mathrm{SiO}_{2}$ \\
\hline Stishovite & Stishovite & $\mathrm{SiO}_{2}$ \\
\hline Ca-Perovskite & Ca-Perovskite & $\mathrm{CaSiO}_{3}$ \\
\hline & & \\
\hline
\end{tabular}

phase change and high-spin/low-spin transition that could occur in the deep lower mantle are also not included $[\mathrm{Mu}$ rakami et al., 2004; Badro et al., 2003, 2004].

The Gibbs free energy $G$ is a function of pressure, $P$, temperature, $T$ and mineralogical composition:

$$
G\left(P, T, n_{i}\right)=\sum_{i=1}^{I} n_{i}(P, T) \mu_{i}\left(P, T, n_{j}, \forall j \in \phi(i)\right),
$$

where $\mu_{i}$ are the chemical potentials of end-members obtained as:

$$
\begin{aligned}
& \mu_{i}\left(P, T, n_{j}, \forall j \in \phi(i)\right)= \\
& \quad \mu_{i}^{0}(P, T)+R T \ln a_{i}\left(P, T, n_{j}, \forall j \in \phi(i)\right),
\end{aligned}
$$

where $\mu_{i}^{0}$ is the standard chemical potential of end-member $i$. The chemical activity $a_{i}$ is a function of the abundances $n_{j}$ of all end-members $j$ belonging to the same phase, $\phi(i)$. The equilibrium composition at given pressure and temperature is obtained by minimizing the Gibbs energy (3), subject to constraints (1) and (2).

The numerical difficulty of solving this minimization problem comes from the fact that it is highly non-linear. For example for end-members in small quantities the activities are generally close to zero. This implies that their chemical potential that includes a logarithm goes discontinuously from $\mu_{0}$ (when the phase is absent) to $-\infty$ (when the phase is in small proportions).

\subsection{Standard chemical potentials and activities}

The standard chemical potentials are easily computed from the thermodynamic and elastic properties: enthalpy of formation, $\Delta H_{f}^{0}$, entropy, $S_{0}$, molar volume, $V_{0}$, room pressure heat capacity, thermal expansion and isothermal incompressibility, $C_{p}(T), \alpha(T)$ and $K_{T, 0}(T)$, pressure dependence of the incompressibility, $K_{T, 0}^{\prime}$, and an equation of state (we use the classical $3^{\text {rd }}$ order finite strain equation of state [Birch, 1952]). In order to compute realistic phase diagrams, the set of parameters must be thermodynamically self-consistent (i.e. obey the Maxwell identities with equalities of the second-order cross-derivatives) and also be in agreement with all accurate observations.

The data selection is a difficult and tedious task (see discussion on lower mantle minerals in Mattern et al. [2005]). For many minerals we had to come back to the original density measurements and fit them in order to obtain the complete set of parameters: $K_{T}, K^{\prime}, \partial K_{T} / \partial T, \alpha(T)$, etc... Indeed, using together parameters bluntly taken from various experimental studies quite systematically fails (i.e. using a molar volume from a given study and a compressibility from a second that did not used the same molar volume leads to thermodynamic inconsistencies). The calorimetry parameters were then refined by comparing the predicted univariant phase diagrams with accurate experimental observations. When adding any new element and solid solution, the predictions were checked as carefully as possible with available experimental data on phase diagrams. The table with 
all thermodynamic and elastic parameters used in this study is available on demand to the authors. Our choice of parameters can certainly, and should be continuously improved by new experiments. As demonstrated below, it however allows us to reproduce the major characteristics of various bulk compositions discussed in the present paper.

For minerals containing aluminum, a special care is taken for their structural and thermodynamic properties at high pressure. In the lower mantle, $\mathrm{Al}$ can be stored in a orthorhombic perovskite solid solution as well as in an exsolved Al-rich phase (for high $\mathrm{Al}$ concentrations like in mid oceanic ridge basalt, MORB). Several potential highpressure phases have been proposed for the exsolved Al, with calcium-ferrite or hollandite-type structures, or with a new hexagonal phase (NAL) (see e.g., Fiquet [2001] for a detailed review and also Gillet [2004], this volume). Some experiments on garnetite assemblage [Irifune et al., 1996; Kubo and Akaogi, 2000; Hirose et al., 2001] suggest that $\mathrm{Al}_{2} \mathrm{O}_{3}$ with corundum structure could be the potential host for the exsolved $\mathrm{Al}$ in the lower mantle. Due to the lack of precise thermodynamic data and equation of state parameters on the high pressure Al-rich phases, we choose the corundum phase as the candidate with the best known properties to evaluate the major effects associated with a possible $\mathrm{Al}$ exsolution.

In addition, for each mineralogical phase a mixing model is also required. In this paper, for binary solid state solutions, empirical activities with Margules coefficients are used [Fei et al., 1991]. For more complex assemblages, due to the lack of experimental data, we adopt an ideal mixingon-site model [Spear, 1995]. This assumes that cations are randomly distributed on the crystallographic sites (as an example, in perovskite the dodecaedric site is randomly occupied by a $\mathrm{Mg}, \mathrm{Fe}$ or $\mathrm{Al}$ cations, the octaedric site by $\mathrm{Al}$ or $\mathrm{Si}$ cations). This mixing model does not assume electro-neutrality at the level of the crystallographic unit cell (i.e., a $\mathrm{Al}^{3+}$ cation can replace a $\mathrm{Mg}^{2+}$ cation). All these activities (empirical or theoretical) take the forms of (often cumbersome) functions of $n_{j}, \forall j \in \phi(i)$. The choice of ideal mixing-on-site activities cannot account for all the mineralogical observations. For example, the demixion of clinopyroxenes into low-Ca and high-Ca components cannot be reproduced by our model, that therefore somewhat underestimates the stability of complex pyroxenes (especially for $\mathrm{Al}$ and Ca-rich compositions).

\subsection{The stoichiometric algorithm}

Our numerical code is adapted from a stoichiometric algorithm proposed by Smith and Missen [1991]. The input is a list of possible mineralogical phases and their corresponding end-members (see Table 1). We assume that the standard potential of all the end-members and their activities are known functions of the variables $P, T$ and $n_{i}$.

The iterative procedure is initiated from a given elementary composition and an arbitrary starting composition, $n_{i}^{0}$ that verifies (1). Here, as the Earth mantle is represented by $I=29$ different components (minerals) and $K=5$ distinct chemical elements (five different oxides), there are $M=29-5=24$ independent reactions that describe all possible evolutions of the system. Let us call $\nu_{i m}$ the coefficients of these $M$ vectors than span the kernel of $S$ (equation 1). Any composition of the form

$$
n_{i}=n_{i}^{0}-\sum_{m=1}^{I-K} \xi_{m} \nu_{i m},
$$

satisfies the element conservation requirement. These coefficients $\nu_{i m}$ are the stoichiometric coefficients of the endmembers $i$ in one of the $M$ possible reactions (the stoichiometric coefficients of the equation $A \rightleftharpoons 2 B$ are 1 and -2). From the definition of the chemical potentials and from the equation (5), we see that the coefficients $\xi_{m}$ control the advancement of the $M$ reactions as

$$
\frac{\partial G}{\partial \xi_{m}}=\sum_{i=1}^{I} \frac{\partial G}{\partial n_{i}} \frac{\partial n_{i}}{\partial \xi_{m}}=-\sum_{i=1}^{I} \mu_{i} \nu_{i m} .
$$

The $m$ right hand members are the affinities of the $I-K$ possible reactions. They are zero at equilibrium. To reach the minimum of $G$, we therefore advance the reactions according to these affinities. As each end-member $i$ can be present in more than one chemical reaction, its total increment $\delta n_{i}$ is therefore proportional to

$$
\delta n_{i}=-\sum_{m=1}^{I-K} \nu_{i m} \sum_{j=1}^{I} \mu_{j} \nu_{j m} .
$$

This advancement procedure (i.e., choosing the $M$ independent reactions, computing their affinities and optimizing the reaction increments in the directions of $\delta n_{i}$ ) is done iteratively until all affinities are zero.

\subsection{Numerical difficulties}

Although the previously described method may seem easy to implement, it is on the contrary a real numerical challenge. Without entering too much into technical details we want to summarize a few important tricks that have to be introduced in order to deal with the complex mantle mineralogies.

3.4.1. Component ordering The choice of the independent reactions is not unique as any linear combination of such reactions is also acceptable. In the set of chemical equations, the left-hand member can be considered as a source and the right-hand members as products. Because of the positivity constraint, equation (2), the advancement of each reaction is therefore limited by the molar abundance of the left-hand members (the sources). For an optimal iteration step the program chooses the set of independent chemical reactions that preferentially puts the most abundant endmembers on the left side of these reactions. 
3.4.2. Treatment of minor end-members of a phase It sometimes happens that a phase of non-negligible abundance contains an end-member in a very small quantity. If this minor end-member is forced to stay on the source side of a chemical reaction the reaction increment decreases significantly. Below a certain threshold, the global properties are no more affected by the presence of a minor endmember. However it is generally not possible to simply assume that its abundance is zero because in that case, its potential (and sometimes those of the other end-members of the same phase) would jump to $-\infty$. The erased endmember would thus be recreated immediately in the next iterative step. In order to avoid such problems, at each iterations, we identify the reactions containing minor phases as sources and their affinities are arbitrarily and momentarily set to zero.

3.4.3. Phase introduction and phase elimination At the beginning or at the end of a phase transformation, special care has to be taken in order to correctly eliminate and/or introduce the appropriate mineralogical phases. We eliminate a whole mineralogical phase if all its end-members are in very small quantities and if their reaction increments are all negative.

The problem of a phase introduction is more complicated. When a phase is not present the activities of its end-members are not yet defined. In other terms, for an absent phase, we only know the $\mu_{i}^{0}$ not the $\mu_{i}$ that enters equation (3.3). At each iteration and for each absent phase, $\phi$, the program must therefore find the virtual chemical potentials, $\mu_{i}^{v}$, of all end-members $i$, that would possibly imply the stability of this phase. Then if the set of equations (see equation (4)),

$$
\mu_{i}^{v}=\mu_{i}^{0}(P, T)+R T \ln a_{i}\left(P, T, n_{j}, \forall j \in \phi(i)\right),
$$

has a solution with $n_{j} \geq 0$ for all the end-members of the absent phase, then all these end-members must be simultaneously introduced in infinitesimal quantities proportional to $n_{j}$.

3.4.4. Elemental conservation When a new phase is introduced or another eliminated, the global elemental composition has to remain constant. A slight correction of the abundances of major end-members is necessary.

\section{Validation of the Method}

The predictions of our numerical code were first systematically tested with simple univariant, then bivariant phase transitions Matas [1999]. This was indeed the method to check and select our thermodynamic data set. Due to the non-linear behavior of the activity coefficients, it is not possible to formally prove that in the general cases with complex non-ideal solid solutions, the code reaches the absolute minimum rather than a secondary local minimum of the freeenergy surface. We have however performed several tests varying the starting end-member composition at constant elementary composition (e.g. starting from $\mathrm{MgO}+\mathrm{SiO}_{2}$, oxide+coesite, or from $\mathrm{MgSiO}_{3}$, perovskite, or from $1 / 2$
Table 2. Global chemical composition of parental mantle (pyrolite) and subducting slab (pyrolite+harzburgite+MORB) in molar fractions of five major simple oxides $\left({ }^{a}\left[\right.\right.$ Ringwood, 1982] ${ }^{b}[$ Ringwood and Irifune, 1988]).

\begin{tabular}{lrcc}
\hline & Pyrolite $^{a}$ & Harzburgite $^{a}$ & MORB $^{b}$ \\
\hline $\mathrm{SiO}_{2}$ & 38.9 & 36.4 & 52.2 \\
$\mathrm{Al}_{2} \mathrm{O}_{3}$ & 2.2 & 0.7 & 10.2 \\
$\mathrm{CaO}$ & 3.1 & 0.9 & 14.8 \\
$\mathrm{MgO}$ & 50.0 & 56.6 & 15.8 \\
$\mathrm{FeO}$ & 5.8 & 5.4 & 7.0 \\
\hline $\mathrm{Mg} / \mathrm{Si}$ & 1.29 & 1.55 & 0.30 \\
$\mathrm{Fe} / \mathrm{Si}$ & 0.15 & 0.15 & 0.13 \\
$\mathrm{Ca} / \mathrm{Si}$ & 0.08 & 0.02 & 0.28 \\
$\mathrm{Al} / \mathrm{Si}$ & 0.11 & 0.04 & 0.39 \\
\hline
\end{tabular}

$\mathrm{Mg}_{2} \mathrm{SiO}_{4}+1 / 2 \mathrm{SiO}_{2}$, forsterite+stishovite,...) always gave the same final composition. The fact that the shape of the Gibbs minimum seems smooth is due to our simplified activity-composition relationships.A more refined modeling should in fact have local minima that are responsible for the immiscibility gaps in $\mathrm{Ca}$ - and Al-rich plagioclase or in clinopyroxene phases.

In order to validate our method for the mantle-like mineralogies, we first discuss the mineralogical and seismologic predictions for various bulk compositions along a given geotherm. We then consider compositions characteristic of a subducting slab.

Underlying the mid oceanic ridge basaltic crust there is a continuous range of depletion from the harzburgite layer to the lherzolite and the pyrolite [Ringwood, 1991]. In this paper, we only compute the phase relationships and bulk physical properties in pyrolite, harzburgite and MORB. Their molar fractions in the different oxides are summarized in Table 2.

Compared to pyrolite, harzburgite is characterized by a lower content in incompatible elements $\mathrm{Al}$ and $\mathrm{Ca}$ (less than $2 \%$ ) and a higher $\mathrm{Mg} / \mathrm{Si}$ ratio (increased by $20 \%$ ) due to higher incompatibility of silicon. In MORB composition, $\mathrm{SiO}_{2}$ represents over $50 \%$ of the whole molar budget whereas $\mathrm{MgO}$ only $15 \%$. The amount of aluminum and calcium in basalt increases fivefold compared to pyrolite.

\subsection{Mineral Proportions along a Geotherm}

The computed phase diagrams (in wt $\%$ ) for three mantle assemblages, pyrolite, harzburgite and MORB, are shown in Figure 3 as a function of depth (vertical axis) (the depthpressure relationship is taken from the PREM model). They are only a simplified summary of the results of our numerical code as the proportions of end-members of each phase are depth dependent. These diagrams are computed along a linear temperature profile with a gradient of $0.3 \mathrm{~K} \mathrm{~km}^{-1}$ cross- 
Pyrolite

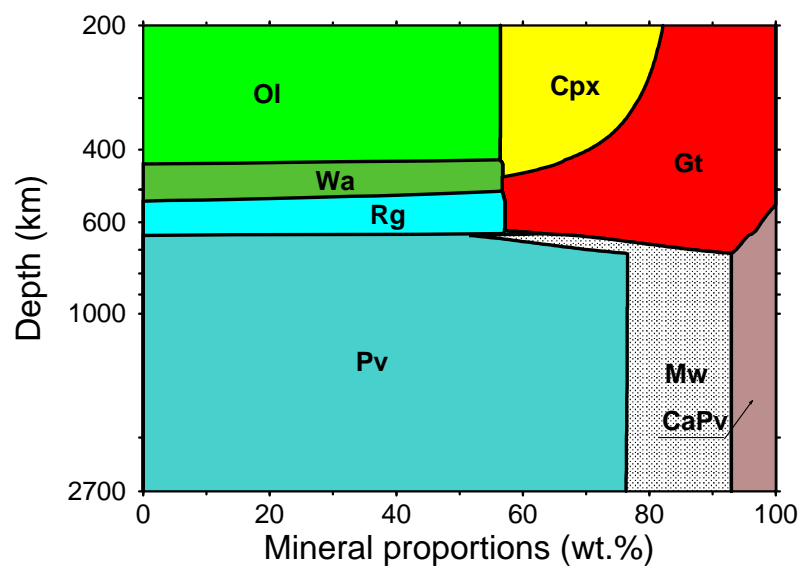

Harzburgite

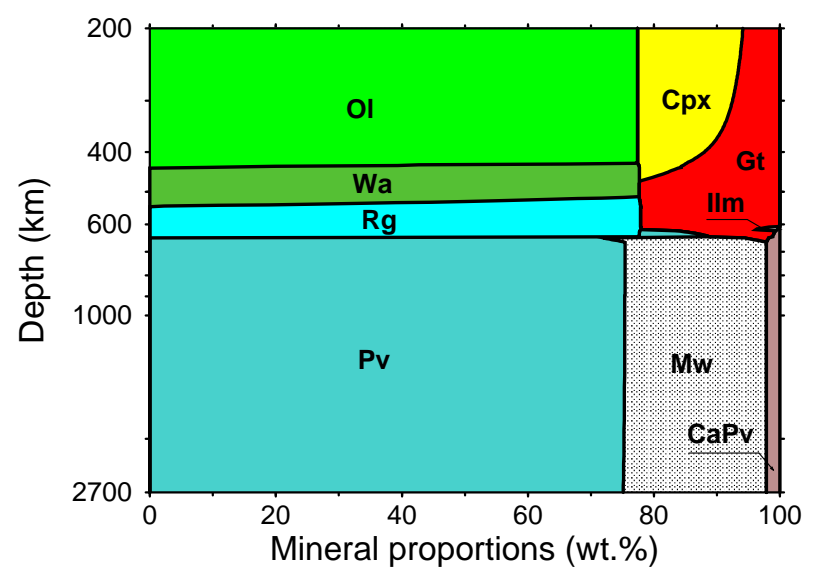

MORB

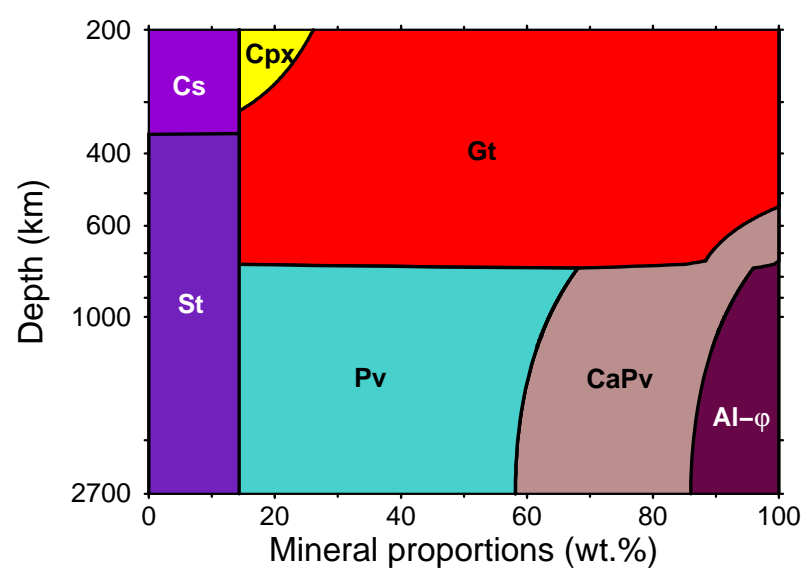

Figure 3. Computed phase diagram for three typical elemental compositions corresponding to pyrolite, harzburgite and MORB (Ol: olivine, Wa: wadsleyite, $\mathrm{Rg}$ : ringwoodite, Pv: perovskite, Cpx: clinopyroxene, Gt: garnet, Mw: magnesiowustite, CaPv: calcium perovskite, Ilm: ilmenite, Cs: coesite, St: stishovite, Al- $\varphi$ : corundum). Notice that for a better visibility over the whole mantle, we use a non-linear scale for depth. The melt residue (Harzburgite) is olivine rich. Silica is an independent phase in MORB (mostly stishovite). In the lower mantle, the aluminum is present in two phases in the oceanic crust ( $\mathrm{Pv}$ and $\mathrm{Al}-\varphi)$. ing the upper-lower mantle interface at $1600{ }^{0} \mathrm{C}$. Our code can also compute the mineralogy along a self-consistent adiabat (i.e. a geotherm that accounts for the heat released or absorbed during phase changes and adiabatic compression). However, there is no profound physical reason for an adiabatic geotherm to be much more realistic one (e.g., Bunge et al. [2001]). Moreover here we only show how mineralogical data can be used: no attempt has been made to precisely match the discontinuities of seismic reflectors or the exact compositions found in mineralogical experiments.

Pyrolite: Figure 3(top)

The phase diagram can be divided into two major classes of minerals: 1) olivine and its high-pressure polymorphs and 2) pyroxene-garnet system. The transition from olivine to wadsleyite is predicted to occur at $430 \mathrm{~km}(14.5 \mathrm{GPa})$ over a narrow range (less than $10 \mathrm{~km}$ or $0.5 \mathrm{GPa}$ ). Wadsleyite dissociates to ringwoodite around $520 \mathrm{~km}(18 \mathrm{GPa})$ over a larger range (greater than $30 \mathrm{~km}$ ). The breakdown of ringwoodite into perovskite and magnesiowustite at $640 \mathrm{~km}(23$ GPa) is very sharp $(\sim 5 \mathrm{~km})$ and can reasonably match the upper-lower mantle discontinuity. Pyroxenes and garnets constitute the second most abundant class of upper mantle minerals and contain almost all the $\mathrm{Al}$ and $\mathrm{Ca}$ budgets. It is by far the most difficult sequence to reproduce, since it requires highly accurate parameters as well as the precise knowledge of activity-composition relationships in complex solid solutions to correctly predict the immiscibility gap and the partitioning of elements between pyroxenes and garnet. As depth increases, clinopyroxenes progressively dissolve into the co-existing garnet phase. At $300 \mathrm{~km}$ depth, the computed garnet is $68 \mathrm{wt} \%$ pyrope, $23 \mathrm{wt} \%$ majorite and $9 \mathrm{wt} \%$ grossular. Complete conversion of clinopyroxenes is achieved at $460 \mathrm{~km}(16 \mathrm{GPa})$. At $600 \mathrm{~km}$ depth, the garnet phase is $56 \mathrm{wt} \%$ majorite-rich, with $29 \mathrm{wt} \%$ pyrope and 15 $\mathrm{wt} \%$ grossular. The garnets are stable over a large pressure range in the pyrolite composition. Above $550 \mathrm{~km}$ (19 GPa), a $\mathrm{CaSiO}_{3}$ perovskite phase exsolves from garnet. The garnet completely transforms to perovskite structure (calcium and magnesium silicate perovskites) above $720 \mathrm{~km}$ depth (26 GPa) whereas the $\mathrm{Al}_{2} \mathrm{O}_{3}$ content is entirely accommodated in Mg-rich perovskite. As a result, the $660 \mathrm{~km}$ discontinuity is made complex by the simultaneous dissociations of ringwoodite and garnet to perovskite phases. At greater depths, the pyrolite assemblage, composed of $76 \mathrm{wt} \%$ perovskite, 17 $\mathrm{wt} \%$ magnesiowustite and $7 \mathrm{wt} \%$ calcium perovskite, is stable throughout the lower mantle, in agreement with a large number of experimental results on pyrolite composition (e.g. see review by Fiquet [2001]). This stability in the phase proportions is however associated with a gradual change in iron partitioning between magnesiowustite and perovskite that favors iron incorporation in perovskite as depth increases, in the presence of aluminum.

Harzburgite: Figure 3(middle)

Similarly to pyrolite, the harzburgite phase diagram may be divided into the olivine and pyroxene-garnet systems. The olivine sequence is rather similar to that of pyrolite. The 
olivine to wadsleyite and wadsleyite to ringwoodite transformations occur slightly deeper in harzburgite than in pyrolite due to a lower iron content. As already observed with pyrolite, the garnet/clinopyroxene ratio gradually increases with depth. The complete dissolution is achieved at similar depth, $460 \mathrm{~km}(16 \mathrm{GPa})$. Increasing depth stabilizes ilmenite over a very narrow region near the base of the transition zone (600 $\mathrm{km})$. Ilmenite rapidly transforms over less than $20 \mathrm{~km}$ depth, into perovskite structure. The garnet to perovskite transformation is completed at around $650 \mathrm{~km}$ depth $(23.5 \mathrm{GPa})$ whereas in pyrolite the garnet persists to $720 \mathrm{~km}(26 \mathrm{GPa})$. This is due to the stabilizing effect of aluminum on garnet. $\mathrm{CaSiO}_{3}$-perovskite is exsolved from garnet at about $600 \mathrm{~km}$ $(21 \mathrm{GPa})$. In the lower mantle, harzburgite is composed of $75 \mathrm{wt} \%$ perovskite, $23 \mathrm{wt} \%$ magnesiowustite and $2 \mathrm{wt} \% \mathrm{cal}-$ cium perovskite. No other phase transition is present in our numerical simulation. These results are consistent with experimental observations of Irifune and Ringwood [1987].

MORB: Figure 3(bottom)

The phase diagram is drastically different from that of harzburgite and pyrolite because the MORB is very silica rich with a $\mathrm{Mg} / \mathrm{Si}$ molar ratio lower than 1 (see Table 2). No olivine polymorph is present. An exsolved $\mathrm{SiO}_{2}$ phase coexists with clinopyroxene and garnet, either as coesite at depths shallower than $360 \mathrm{~km}(12 \mathrm{GPa})$ or as stishovite at larger depths. Notice that the computation are performed far above the stability field of plagiclase. Since we do not consider any other silica-rich phase such as high-pressure hollandite structures [Fiquet, 2001], stishovite is then found in the same proportion throughout the mantle. The dissolution of clinopyroxene into garnet is achieved at lower pressure than in pyrolite (around $310 \mathrm{~km}$ or $10 \mathrm{GPa}$ instead of $460 \mathrm{~km}$ or $16 \mathrm{GPa}$ ). The stability field of pyroxene is too shallow compared to experiments. This seems to be related to the difficulty of having realistic activity models for the end-members of pyroxenes. The proportion of garnet starts to decrease at 540 $\mathrm{km}(18.5 \mathrm{GPa})$ due to exsolving $\mathrm{CaSiO}_{3}$-perovskite. Around $740 \mathrm{~km}(27 \mathrm{GPa})$, the Al-rich phase appears when garnet becomes unstable. $\mathrm{Al}$ is incorporated into both perovskite and corundum. The garnet-perovskite coexisting field is relatively narrow (less than $15 \mathrm{~km}$ ) compared to that of the garnet-perovskite transformation in the pyrolite and harzburgite compositions. The garnet-perovskite transformation is completed around $760 \mathrm{~km}$ depth (28 GPa) which is consistent with experimental study by Hirose et al. [1999] and with the fact that high $\mathrm{Al}$ content stabilizes garnet in the lower mantle. Through the lower mantle after garnet vanishes, aluminum is exchanged between the two Al-bearing high-pressure phases (corundum/perovskite) favoring its incorporation into the corundum phase. In the lower mantle, the MORB composition crystallizes into an assemblage of $44 \mathrm{wt} \%$ Al-bearing perovskite, $28 \mathrm{wt} \%$ calcium perovskite, $14 \mathrm{wt} \%$ stishovite, and $14 \mathrm{wt} \%$ Al-rich phase. This is in agreement with recent experiments performed with similar MORB composition [Perrillat et al., 2004; Ricolleau et al., 2004].
Our thermodynamic approach allows us to reasonably reproduce the experimental phase diagrams. However, several observations are not well explained and underline the potential shortcoming of our approach. Our data base does not predict the presence of low-Ca pyroxenes in pyrolite and harzburgite as observed [Irifune and Isshiki, 1998; Irifune and Ringwood, 1987]. The computed stability field of clinopyroxene in MORB is too narrow compared to experiments that indicate the coexistence of garnet and clinopyroxene to $460 \mathrm{~km}$ (16 GPa) [Aoki and Takahashi, 2004]. A third Al-rich phase (NAL phase) seems to be locally present after garnet disappear in MORB [Perrillat et al., 2004]. A more precise mineralogical modeling would be requested to resolve these discrepancies. The fundamental advantage of our method is that it however allows us to make predictions of phase diagrams when, composition, pressure and temperature are continuously varied, which is beyond practical possibility for experimental techniques.

\subsection{Radial density and velocity profiles}

From the computed equilibrium mineralogies, we can deduce density $\rho$, isothermal incompressibility, adiabatic incompressibility $K_{S}$, and bulk sound velocity $V_{\phi}=\sqrt{K_{S} / \rho}$ of pyrolite (green), harzburgite (red) and MORB (blue) compositions as a function of depth (see Figure 4). The incompressibility shown in this figure corresponds to a Reuss average for an assemblage [Watt et al., 1976]. The same arbitrary geotherm is used for the three mineralogies. For reference, PREM values are also depicted (black). Notice that we have not tried in this paper to fit PREM with any of the mineralogical models by varying the temperature profile or the bulk composition (see Mattern et al. [2005]).

Density: Figure 4(top)

In the upper mantle, the ancient basaltic crust is denser than both pyrolite and harzburgite by around $0.1-0.2 \mathrm{~g} \mathrm{~cm}^{-3}$. This is due to the large content of dense garnet and to the presence of the even denser stishovite. Between 645 and $760 \mathrm{~km}$ depth basaltic crust becomes on the contrary, lighter by about $0.2 \mathrm{~g} \mathrm{~cm}^{-3}$ in agreement with observations [Irifune and Ringwood, 1993; Hirose et al., 1999]. These large buoyancy variations are due to the different sequences of garnetperovskite as discussed above. Indeed, the garnet is $\sim 10 \%$ lighter than perovskite. Once the transformation of garnet to perovskite is completed (at about $760 \mathrm{~km}$ depth) MORB is no longer buoyant and its density becomes again higher than that of pyrolite. The density excess is about $0.1 \mathrm{~g} \mathrm{~cm}^{-3}$ at the top of the lower mantle and decreases to about 0.03 $\mathrm{g} \mathrm{cm}^{-3}$ near the CMB. This excess density is large compared to thermal density anomalies: as we predict a thermal expansivity of $0.710^{-5} \mathrm{~K}^{-1}$ in the lowermost mantle, a temperature increase of $\sim 800 \mathrm{~K}$ is necessary for a subducted MORB to become neutrally buoyant. Harzburgite is by $0.02-$ $0.05 \mathrm{~g} \mathrm{~cm}^{-3}$ slightly less dense than pyrolite throughout the mantle. The low $\mathrm{FeO}, \mathrm{Al}_{2} \mathrm{O}_{3}$ and $\mathrm{CaO}$ contents lead to smaller amounts of garnets above $530 \mathrm{~km}$ depth of the very dense $\mathrm{CaSiO}_{3}$-perovskite. However, between 640 and 700 

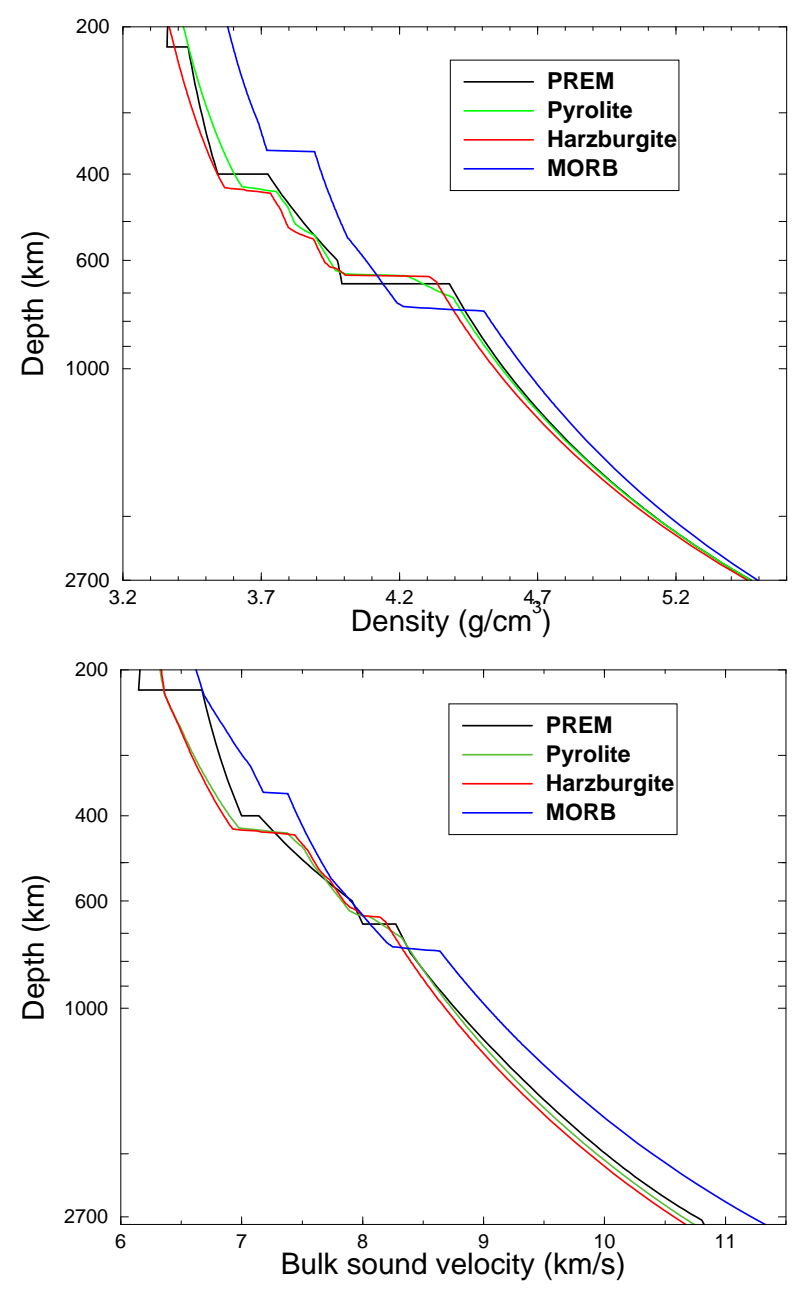

Figure 4. Computed density $\rho$ and bulk sound velocity $V_{\phi}$ as a function of depth for pyrolite, harzburgite and MORB compositions. Seismic profiles given by PREM [Dziewonski and Anderson, 1981] are also plotted. The mineralogical predictions have been computed assuming that the temperature increases linearly with depth. The choice of a non-linear scale induces an apparent curvature of the profiles. The pyrolite composition gives a close fit to PREM. The eclogitized MORB is very significantly denser and faster than the average mantle except in a limited range below the upper-lower mantle interface. $\mathrm{km}$ depth, harzburgite is slightly denser (by $0.04 \mathrm{~g} \mathrm{~cm}^{-3}$ ) than pyrolite because of the sharp transformation of ringwoodite+garnet to perovskite+magnesiowustite assemblage at $640 \mathrm{~km}$. This is in good agreement with the experimental results obtained by Ringwood [1991], Irifune and Ringwood [1987], and Irifune and Ringwood [1993]. On average, the crust and the corresponding depleted lithosphere have together the same average density as pyrolite, at the same temperature.

Bulk sound velocity: Figure 4(bottom)

In the upper mantle, the MORB composition is faster than both pyrolite and harzburgite by about $0.2 \mathrm{~km} \mathrm{~s}^{-1}$. This is due to the large content of garnet, particularly pyrope and grossular, as well as the presence of fast stishovite. Between 645 and $750 \mathrm{~km}$ depth basaltic crust becomes on the contrary slower by about $0.1 \mathrm{~km} \mathrm{~s}^{-1}$ due to the persistence of garnets. Below $800 \mathrm{~km}$, the basaltic crust becomes faster than an average lower mantle, with a velocity profile which slightly diverges from that of pyrolite due to the progressive exchange of $\mathrm{Al}$ from perovskite to corundum phases. This last prediction should however be taken with caution because it is based on our simplified model for the Al-rich phase in the lower mantle. More precise predictions of the velocity differences and of their behavior with depth would need accurate measurements of the elastic properties of the aluminum rich phase which are not available at present. The depleted mantle (harzburgite) has almost the same velocity as the parental mantle (pyrolite): the difference is between $-0.06 \mathrm{~km} \mathrm{~s}^{-1}$ and $+0.06 \mathrm{~km} \mathrm{~s}^{-1}$ in the upper mantle and is constant close to $-0.06 \mathrm{~km} \mathrm{~s}^{-1}$ in the lower mantle.

\section{Application to slab penetration modeling}

Our mineralogical model can be also used to compute density and bulk sound velocity of a hypothetical subducting slab. We consider a $100 \mathrm{~km}$ thick mature oceanic lithospheric plate far from an oceanic rift, across which there is a linear temperature difference of $1000 \mathrm{~K}$. This initial thermal structure is then modified by heat diffusion once the plate enters vertically into the mantle with a constant vertical velocity of $5 \mathrm{~cm} \mathrm{yr}^{-1}$. We consider a uniform thermal diffusivity $\kappa=10^{-6} \mathrm{~m}^{2} \mathrm{~s}^{-1}$ and no heat source. We neglect vertical diffusion and only consider lateral thermal effect. In the mantle, far from the slab, we use a linear geotherm (a gradient of $0.3 \mathrm{~K} \mathrm{~km}^{-1}$ with a surface temperature of $1400{ }^{0} \mathrm{C}$ ). We do not consider the possible thickening of the slab entering the lower mantle as suggested by geodynamical modeling. Our slab model is certainly very simple and we could have imposed a more realistic subduction angle but this would not have significantly affected our conclusions.

At each point, according to the local temperature and pressure, we compute the equilibrium mineralogy as discussed before. We consider two distinct cases: 1) the whole slab has pyrolite composition and 2) the slab is made of 50 $\mathrm{km}$ of pyrolite, $40 \mathrm{~km}$ of harzburgite and $10 \mathrm{~km}$ of MORB (the mixing of $4 / 5$ harzburgite with 1/5 MORB gives approx- 
imately the pyrolite composition).

The thermo-chemical approach gives the density, the incompressibility and the bulk sound velocity, but not the shear modulus $\mu$ needed to compute the seismic velocities $v_{S}$ and $v_{P}$. Although Brillouin and ultrasonic measurements of rigidity start to be available (e.g., Sinogeikin and Bass [2002]; Kung et al. [2002]; Jackson et al. [2004]), a complete data set for all the end-members introduced in our modeling is still missing. We therefore assume a simple semiempirical model for the the rigidity. The lateral variations of rigidities have two components. The first one has a thermal origin at constant composition,

$$
\Delta \mu / \mu=-(a+b z) 10^{-5} \Delta T,
$$

where $z$, in $\mathrm{km}$, is depth. In relative agreement with the few experimental studies we take $a=21.3$ and $b=-0.0055$ $\mathrm{km}^{-1}$. The second is related to changes in mineralogy,

$$
\Delta \mu / \mu=c \Delta K_{S} / \mu,
$$

with $c=0.631$ according to Stacey [1992], and where $\Delta K_{S}$ is the difference between the incompressibilities of the slab and of the normal mantle due to their differences of mineralogies. The shear velocities are certainly more affected than the compressional velocities by this poor modeling of rigidity. This is why we have chosen in the next paragraphs to only discuss our results in terms of sound velocity $v_{\phi}$ (independent of the rigidity model) and compressional velocity $v_{P}$ for comparison with Figure 2.

\subsection{Pyrolite slab}

In Figure 5 we show the computed temperature, the density excess $\Delta \rho / \rho$ and the equivalent tomographic images $\Delta v_{\phi} / v_{\phi}, \Delta v_{p} / v_{p}$ within a subducting slab and the surrounding mantle as a function of depth and horizontal distance. The temperature map (top left) shows the progressive reheating of the slab with depth. Notice that with a vertical slab velocity is $5 \mathrm{~cm} \mathrm{yr}^{-1}$, at $2200 \mathrm{~km}$ depth, the slab is still not thermally re-assimilated (the coldest part of the slab is still colder by $350 \mathrm{~K}$ ).

The relative density difference (in \%) between subducting slab and surrounding mantle far from this cold region is shown in the top right panel of Figure 5. One can recognize two major contributions to the observed density heterogeneities. On the one hand, cold material is denser due to the intrinsic thermal contribution. As an example, the central part of the slab is about $2 \%$ denser at $200 \mathrm{~km}$ depth and $0.4 \%$ denser at $2200 \mathrm{~km}$. This is both due to the diffusion of heat toward the center of the slab and to the decrease of thermal expansivity with depth (that decreases from $3.210^{-5}$ $\mathrm{K}^{-1}$ in the olivine stability field to $0.710^{-5} \mathrm{~K}^{-1}$ near the core mantle boundary). On the other hand, there are effects on density due to the phase transformations the occur in the slab at a shallower depth for exothermic phase changes with positive Clapeyron slope, and deeper for endothermic phase change with negative Clapeyron slope. Since the $410 \mathrm{~km}$

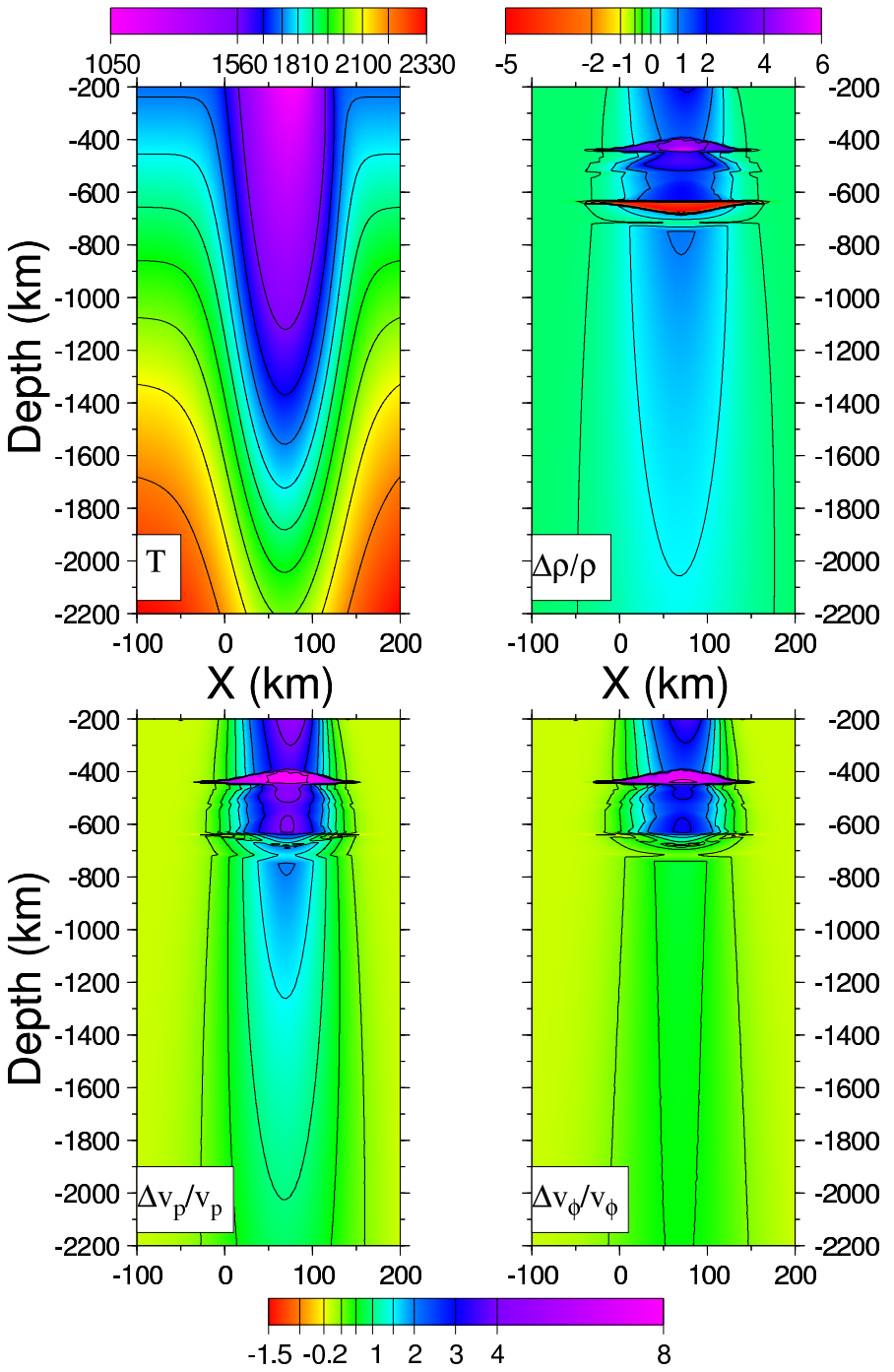

Figure 5. Temperature (K), lateral density and velocity variations (\%), associated with a slab sinking vertically in the mantle. The surface of the slab is initially at $x=0$. The temperature variation have been simply computed assuming diffusive re-heating for a $100 \mathrm{~km}$ thick slab sinking at 5 $\mathrm{cm} /$ year. Far from the slab, we assume that the background temperature varies linearly with depth following a typical adiabat. We assume that the slab is composed of pure pyrolite The density and velocities are deduced from our Gibbs minimization procedure. 

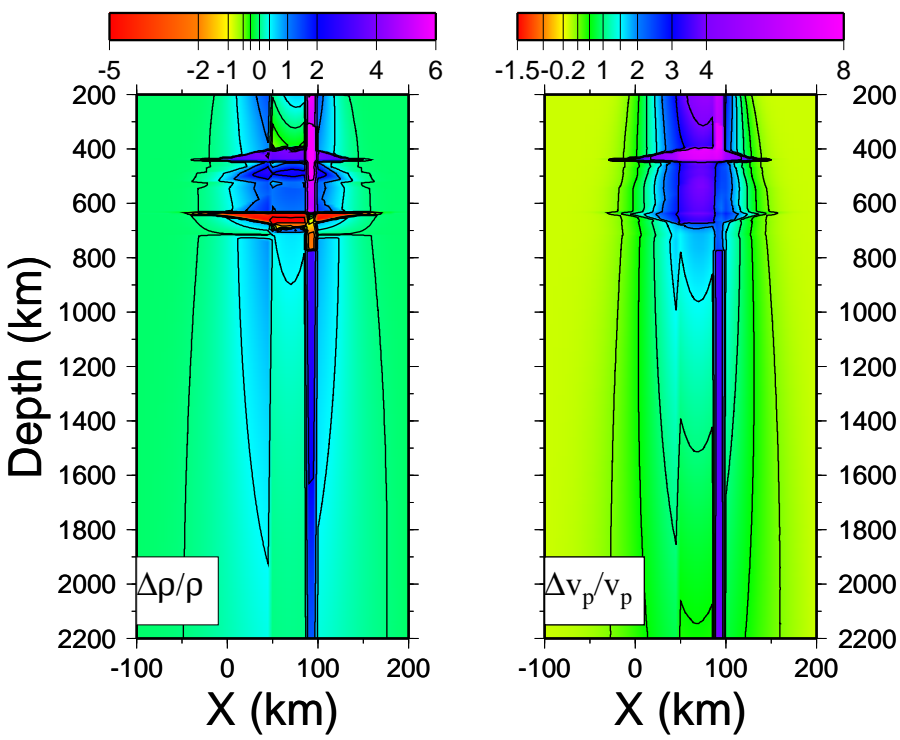

Figure 6. Lateral density and P-velocity variations associated with a slab sinking vertically in the mantle. Compare to Figure 5, the slab now includes a $10 \mathrm{~km}$ thick oceanic crust (MORB composition) overlying a $40 \mathrm{~km}$ thick depleted lithosphere (harzburgitic composition).

and $520 \mathrm{~km}$ discontinuities have positive Clapeyron slopes, they occur at lower depths in the cool slab inducing an additional increase of density of $5 \%\left(0.18 \mathrm{~g} \mathrm{~cm}^{-3}\right)$ at $430 \mathrm{~km}$ and of $2.8 \%\left(0.11 \mathrm{~g} \mathrm{~cm}^{-3}\right)$ at $500 \mathrm{~km}$. This effect is not localized at one depth but forms a large zone of excess density from 390 to $520 \mathrm{~km}$. The density contrast is opposite in the depth range from 630 to $690 \mathrm{~km}$ with a maximum difference of $-5 \%\left(-0.22 \mathrm{~g} \mathrm{~cm}^{-3}\right)$ due to the endothermic decomposition of ringwoodite. The latter effect resists to convective downwellings but should not be large enough to impede slab penetration [Christensen, 1996].

The two bottom panels of Figure 5 depict the predicted seismic velocity perturbations in \%. The lost of amplitude by a factor $\sim 3$ when the slab enters the lower mantle is the main indication of this modeling in agreement with Goes et al. [2004]. In the upper mantle, we observe strong lateral variations (at least a few \%) due to the combined thermal and phase change effects. The subducting slab becomes significantly less visible in the lower mantle. At $2000 \mathrm{~km}$ depth, lateral variations within the slab are at most $0.5 \%$ for $v_{P}$ and $1 \%$ for $v_{S}$. The velocity anomalies are affected by the phase changes in the upper mantle but the details may not be realistic due to the poor quality of our modeling of rigidities.

\subsection{Composite slab}

A more realistic slab petrology is considered, in Figure 6. We only represent the density and P-wave velocity perturbations in $\%$. The temperature remains the same as in Figure 5 (top left panel). The thermal density excess (Figure 6(left)) is partially balanced by the compositional effect in the harzburgitic lithosphere. The situation is very different in the 10-km thick MORB layer which is much denser than the pyrolytic mantle (4\% above $640 \mathrm{~km}$ depth and $\sim 2.2 \%$ below $780 \mathrm{~km}$ ). In between, due to the persistence of garnet, the MORB layer becomes buoyant as discussed previously $(-1.5 \%)$. Horizontally averaged, the excess mass and velocity of a composite slab is very similar to that of a slab of pure pyrolitic composition, in other words, the basalt together with the corresponding depleted lithosphere have properties roughly equivalent to those of the parental mantle. However the behavior in the convective mantle of a composite slab cannot be understood from a simple thermo convective model. During subduction, the dense crustal layer may delaminate from the rest of the lithosphere and segregate at depth. This dynamics is observed in numerical simulations and has been invoked to explain various geochemical observations [Christensen and Hofmann, 1994; Coltice and Ricard, 1999].

\subsection{The origin of density and velocity anomalies}

The lateral variations of any property in the mantle $\Delta f$, ( $f$ standing for density, thermal expansivity, incompressibility, seismic velocity...) have potentially three contributions that can be summarized as

$$
\begin{gathered}
\Delta f=\left(\frac{\partial f}{\partial T}\right)_{\phi} \Delta T+\left(\frac{\partial f}{\partial \phi}\right)_{T}\left(\frac{\partial \phi}{\partial T}\right)_{\chi} \Delta T+ \\
\left(\frac{\partial f}{\partial \phi}\right)_{T}\left(\frac{\partial \phi}{\partial \chi}\right)_{T} \Delta \chi .
\end{gathered}
$$

This first term on the right hand side, is the intrinsic thermal effect that is computed at constant mineralogical proportions (symbolized by the subscript $\phi$ ). The second term is a thermo-chemical effect and corresponds to the changes in mineral proportions necessary to maintain the Gibbs equilibrium at constant elemental (bulk) composition. This term is responsible for a rise of the $410 \mathrm{~km}$ depth interface and deepens the $650 \mathrm{~km}$ depth interface in the presence of cold downwellings Irifune and Ringwood [1987]. However except for these two quasi univariant phase changes, previous studies have not considered this effect for larger phase transitions (e.g. olivine/ringwoodite), continuous phase changes (e.g. pyroxene/garnet and garnet/perovskite), or changes in partition coefficients with depth (e.g. perovskite/magnesiowustite). The last term of equation (11) is the intrinsic chemical effect (variations in the elemental budget, symbolized by $\chi$, at constant temperature). Any change in the bulk elementary composition affects the mineralogical composition at constant temperature and can, therefore, contribute to lateral variations of $f$.

If the mantle average phase content is known the first contribution can be estimated. The last two contributions can however be precisely evaluated only by using a Gibbs freeenergy minimization techniques. Computing the changes in mineralogy with temperature requires to take into account precisely various phase equilibria and to introduce, if necessary, new mineralogical phases not stable at the reference 
temperature. In the same way, assuming for example an enrichment in iron in the lower mantle would not affect the properties in the same way assuming that the iron goes preferentially into perovskite or into magnesiowustite. The effect of iron implicitly requires the knowledge of the $P, T$ and Al-dependent partition coefficients (the chemical activity of iron in perovskite in indeed function of its aluminum content).

We depict in Figure 7 the three contributions of equation (11) for density (left column) and $v_{\phi}$ velocity (right column). The reference state is the pyrolitic mantle. The top row is the intrinsic thermal effect due to the presence of a cold slab while the mineralogy is hold constant. The second row is the contribution due to phase changes and changes in mineralogical composition imposed by temperature variations within and around the slab. The sum of these two contributions (thermal and thermo-chemical) is depicted in the right column of Figure 5. Although a simple model that would move the main phase transition according to their Clapeyron slopes would catch some important mineralogical contributions, it is clear from Figure 7 that all phase changes contribute to the total properties: not only the olivine/wadsleyite and ringwoodite/perovskite + magnesiowustite but also the wadsleyite/ringwoodite phase change and all those involving pyroxene, garnet and Ca-Perovskite. The dissolution of pyroxene into garnet seems to significantly affect the bulk sound velocity not the density. On the contrary, the phase transition between wadsleyite and ringwoodite around 520 $\mathrm{km}$ depth has a significant influence on the densities without affecting the velocities very much. Notice also that even in the lower mantle there is a minute contribution to the velocity anomaly due to the progressive enrichment in iron of the perovskite phase (the level line in the middle right panel of Figure 7 is $-0.05 \%$ ). The bottom row represents the intrinsic chemical heterogeneities that are associated with a composite slab without any lateral temperature variations. Notice that the same color scale is used for the three contributions which emphasizes the fact that thermal, thermochemical and chemical anomalies are of the same order.

\subsection{Effect of elemental variations on density and velocity anomalies}

The properties of subducted MORB are so different from those of pyrolite that we did not predict them by simply extrapolating from the pyrolite properties using the differential form (11). In other terms, the $\Delta \chi$ between MORB and pyrolite are not infinitesimal. We directly computed the MORB and pyrolite properties without explicitly using partial derivatives. However, it is also possible that the chemical composition of the lower mantle evolves continuously around its average composition with progressive, lateral or depth dependent chemical variations. Typically this is the case when the observed seismic tomography is to be interpreted in terms of smooth laterals variations of temperature and bulk chemical composition. To formulate properly the inverse problem one has to know precisely all the partial

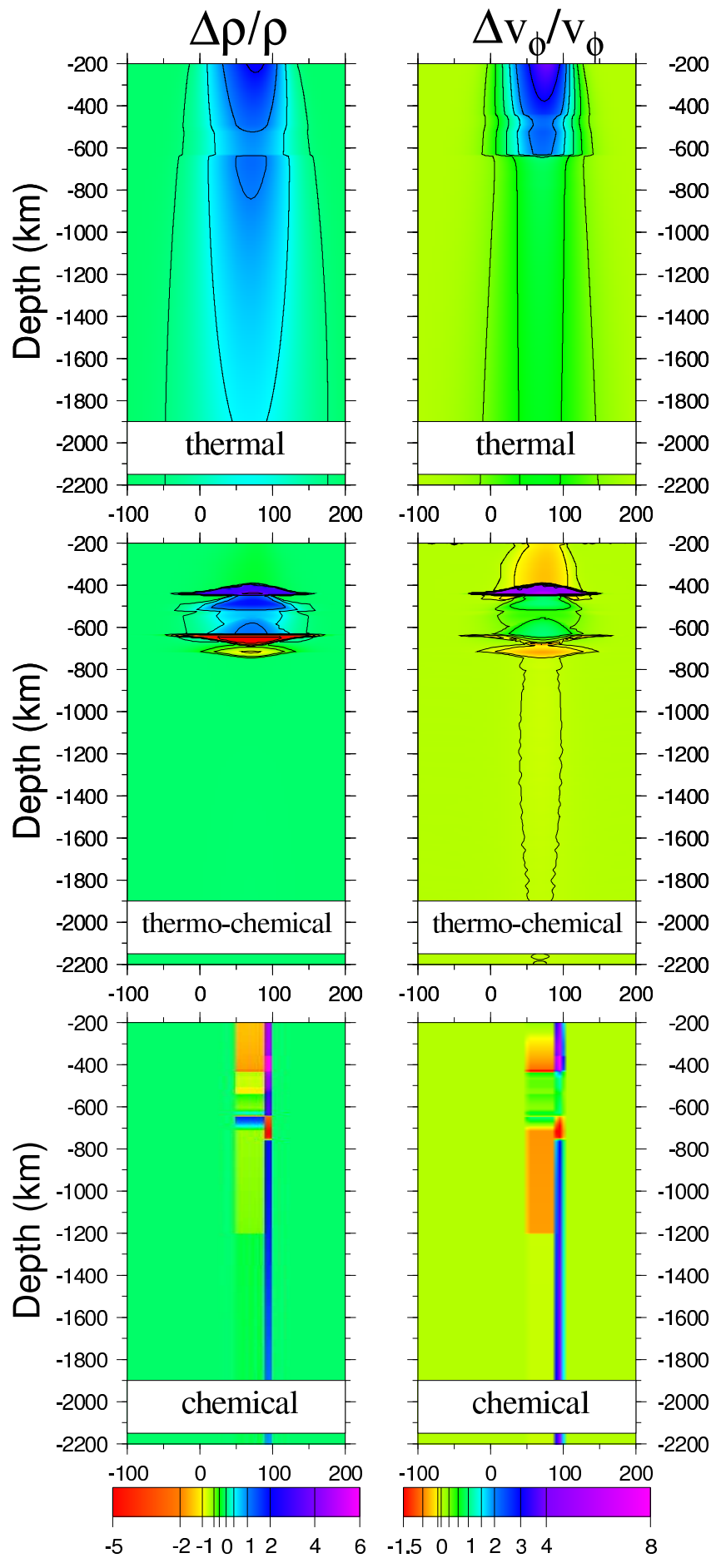

Figure 7. The density (left) and $v_{\phi}$ velocity (right) anomalies in a subducting slab have three origins; an intrinsic thermal origin (changes of properties with temperature at constant mineralogical content, top row), a thermo-chemical origin (phase changes and changes in phase composition induced by temperature anomalies, middle row), an intrinsic chemical effect (changes in elementary composition, bottom row). The three contributions have basically similar amplitudes. In the two top rows, the slab has a pure pyrolitic composition and the same temperature as in Figure 5. The bottom row is the difference in properties at the same temperature between a composite slab and a pyrolite slab. 
Table 3. Partial derivatives of $\ln \rho, \ln v_{p}$ or $\ln v_{\phi}$ with respect to temperature (in $\mathrm{K}$ ) and mole abundances of oxides. Two depths have been considered, 1030 and $2060 \mathrm{~km}$, the reference case is pyrolite at $2000 \mathrm{~K}$.

\begin{tabular}{lccc}
\hline $1030 \mathrm{~km}$ & $\ln \rho$ & $\ln v_{\phi}$ & $\ln v_{p}$ \\
\hline $\mathrm{d} / \mathrm{dT}$ & $-1.84710^{-5}$ & $-1.72910^{-4}$ & $-1.94010^{-4}$ \\
$\mathrm{~d} / \mathrm{d}(\mathrm{MgO})$ & -0.087 & -0.071 & -0.080 \\
$\mathrm{~d} / \mathrm{d}(\mathrm{FeO})$ & 0.449 & -0.342 & -0.351 \\
$\mathrm{~d} / \mathrm{d}\left(\mathrm{Al}_{2} \mathrm{O}_{3}\right)$ & -0.209 & 0.085 & 0.084 \\
$\mathrm{~d} / \mathrm{d}(\mathrm{CaO})$ & -0.038 & -0.097 & -0.106 \\
$\mathrm{~d} / \mathrm{d}\left(\mathrm{SiO}_{2}\right)$ & 0.060 & 0.145 & 0.159 \\
\hline $2060 \mathrm{~km}$ & $\rho$ & $v_{\phi}$ & $v_{p}$ \\
\hline $\mathrm{d} / \mathrm{dT}$ & $-1.13710^{-5}$ & $-1.68410^{-4}$ & $-1.96910^{-4}$ \\
$\mathrm{~d} / \mathrm{d}(\mathrm{MgO})$ & -0.061 & -0.060 & -0.072 \\
$\mathrm{~d} / \mathrm{d}(\mathrm{FeO})$ & 0.475 & -0.330 & -0.342 \\
$\mathrm{~d} / \mathrm{d}\left(\mathrm{Al}_{2} \mathrm{O}_{3}\right)$ & -0.208 & 0.087 & 0.084 \\
$\mathrm{~d} / \mathrm{d}(\mathrm{CaO})$ & -0.015 & -0.036 & -0.042 \\
$\mathrm{~d} / \mathrm{d}\left(\mathrm{SiO}_{2}\right)$ & 0.020 & 0.125 & 0.142 \\
\hline
\end{tabular}

derivatives at given depth [Trampert et al., 2004]

In Table 3, we show the values of $(\partial \ln f / \partial T)_{\chi}$ and $(\partial \ln f / \partial \chi)_{T}$ at two depths, 1030 and $2060 \mathrm{~km}$. Here $f$ stands for $\rho, v_{p}$ or $v_{\phi}, \chi$ is the mole abundance in oxides $\mathrm{MgO}, \mathrm{FeO}, \mathrm{SiO}_{2}, \mathrm{Al}_{2} \mathrm{O}_{3}$ and $\mathrm{CaO}$ (except for the factor 2 in $\mathrm{Al}_{2} \mathrm{O}_{3}$, it is also the mole abundance in cations). These derivatives are computed under thermodynamic equilibrium. The reference state has a pyrolite composition and a reference temperature of $2000 \mathrm{~K}$. One can see that the values of the individual partial derivatives with the composition are rather constant with depth. The values confirms that iron and temperature are the two most sensitive parameters in terms of density and velocity variations (e.g. Mattern et al. [2005]; Trampert et al. [2004]). In the case of the derivatives with respect to temperature and iron, our values are comparable but larger in amplitude to those of Trampert et al. [2004] and Forte and Mitrovica [2001], particularly for $v_{\phi}$. The Table shows that the partial derivatives with respect to aluminum even though being lower than that with respect to iron, are not negligible specially for the density and have opposite signs. It follows that the effect of aluminum should be considered when interpreting the tomographic images. Finally, one can also see that the least sensitive parameter for the density is calcium.

\section{Conclusions}

The simple visual inspection of tomographic sections across subduction zones is not a definitive argument for slab penetration unless a precise modeling of temperaturevelocity relationship is done. The velocity amplitude reduction by a factor $\sim 3$ across the upper-lower mantle interface observed locally in various tomographic model (see Figure
2) is however in good agreement with what can be estimated from mineral physics (see Figure 5, bottom left).

The computed phase diagrams do not explain all mineralogical details that have been experimentally observed. In spite of these problems it seems to us that the general agreement of the mineralogical predictions with various observations and the good fit with seismology is a remarkable success. It proves the high accuracy of the available thermo-chemical data and gives the exciting indication that these data will be soon integrated into complex geodynamical models. Understanding the dynamics of mantle reservoirs with different composition/petrology is indeed necessary to explain the complexities of geochemical observations [van Keken and Ballentine, 1998; Ricard and Coltice, 2004; Tackley, 2000]. Figure 7 however, illustrate the fact that this integration must be done on the basis of thermodynamical principle, not by assuming an a priori depth dependent mineralogy. The temperature, the trajectory, the possible thickening of slabs crossing the transition zone should not be guessed from a simple diffusive model as we did, but self consistently deduced from momentum and energy considerations.

The simulation of a complex slab mineralogy that we presented here is very crude. The depletion of the lithosphere is a continuous process without abrupt compositional transition between the parental fertile mantle and the most depleted harzburgitic layer. Although the uncertainties are probably large, our selection of the best available data does not show any crossover with depth between the densities of pyrolite, harzburgite and MORB. As seen of Figure 6 the crust remains denser while the cold depleted layer is basically neutrally buoyant. Although the variations in Fe and temperature are the major sources of seismic velocity variations, the other variations in bulk composition cannot be neglected.

Acknowledgments. We would like to thank Rob van der Hilst and Chang Li that made their tomographic model and the associated numerical tools available to us to draw Figure 2. This work also benefited from numerous discussions with Franois Guyot, Philippe Gillet, Guillaume Fiquet, Nicolas Coltice and Jay Bass. We also thank Saskia Goes and another anonymous colleague for their very constructive and detailed reviews. 


\section{References}

Aoki, I., and E. Takahashi (2004), Density of MORB in the upper mantle, Phys. Earth Planet. Inter., 143-144, 129-143.

Badro, J., G. Fiquet, and F. Guyot (2003), Iron partitioning in earth's mantle: Toward a deep lower mantle discontinuity, Science, 300, 789-791.

Badro, J., J.-P. Rueff, H. Reniewicz, G. Fiquet, and F. Guyot (2004), Electronic transitions in perovskite: possible nonconvecting layers in the lower mantle, Science, 305, 383.

Barron, L. M. (1968), Thermodynamic, multicomponent silicate equilibrium phase calculations, Am. Miner., 57, 809-823.

Becker, T. W., and L. Boschi (2002), A comparison of tomographic and geodynamic mantle models, Geochem. Geophys. Geosyst., 3, 2001GC000,168.

Bercovici, D., Y. Ricard, and M. Richards (2000), The relation between mantle dynamics and plate tectonics: A primer, in: History and Dynamics of Global Plate Motions, Geophys. Monogr. Ser., vol. 121, 5-46 pp., M.A. Richards, R. Gordon, and R. van der Hilst, AGU, Washington D.C.

Berman, R. G., and T. H. Brown (1985), A thermodynamic model for multicomponent melts, with application to the system $\mathrm{CaO}-\mathrm{Al}_{2} \mathrm{O}_{3}-\mathrm{SiO}_{2}$, Geochim. Cosmochim. Acta, 49, 613-614.

Bijwaard, H., and W. Spakman (2000), Non-linear global p-wave tomography by iterated linearized inversion, Geophys. J. Int., 141, 71-82.

Bina, C. R., and B. J. Wood (1986), The 400-km seismic discontinuity and the proportion of olivine in the earth's upper mantle, Nature, 324, 449-451.

Birch, F. (1952), Elasticity and constitution of the earth's interior, J. Geophys. Res., 57, 227-286.

Bottinga, Y., and P. Richet (1978), Thermodynamics of liquid silicates, a preliminary-report, Earth Planet. Sci. Lett., 40, 382-400.

Bunge, H. P., Y. Ricard, and J. Matas (2001), Non-adiabaticity in mantle convection, Geophys. Res. Lett., 28, 879-882.

Christensen, U. R. (1996), The influence of trench migration on slab penetration into the lower mantle, Earth Planet. Sci. Lett., 140, 27-39.

Christensen, U. R., and A. Hofmann (1994), Segregation of subducted oceanic crust in the convecting mantle, J. Geophys. Res., 99, 19,867-19,884.

Coltice, N., and Y. Ricard (1999), Geochemical observations and one-layer mantle convection, Earth Planet. Sci. Lett., 174, 125-137.

Davies, G. F. (1988), Ocean bathymetry and mantle convection, 1, large scale flow and hotspots, J. Geophys. Res., 93, $10,467-10,480$.

Davies, G. F., and M. Richards (1992), Mantle convection, J. Geol., 100, 151-206.

Dziewonski, A. M., and D. Anderson (1981), Preliminary reference earth model, Phys. Earth Planet. Inter., 25, 297-356.

Fabrichnaya, O. B., and O. L. Kuskov (1991), Constitution of the mantle. 1. phase-relations in the $\mathrm{FeO}-\mathrm{Mg} 0-\mathrm{SiO}_{2}$ system at 10-30 GPa, Phys. Earth Planet. Inter., 69, 56-71.

Fei, Y., H.-K. Mao, and B. Mysen (1991), Experimental determination of element partitioning and calculation of phase relations in the mgo-feo-sio 2 system at high pressure and high temperature, J. Geophys. Res., 96(B2), 2157-2169.

Fiquet, G. (2001), Mineral phases of the earth's mantle, Z. Kristallogr, 216, 248-271.

Fiquet, G., F. Guyot, M. Kunz, J. Matas, D. Andrault, and M. Hanfland (2002), Structural rafinements of magnesite at very high pressure, Amer. Mineral., 87, 1261-1265.

Forte, A. M., and J. Mitrovica (2001), Deep-mantle high-viscosity flow and thermochemical structure inferred from seismic and geodynamic data, Nature, 410, 1049-1056.

Fukao, Y., M. Obayashi, H. Inoue, and M. Nenbai (1992), Subducting slabs stagnant in the mantle transition zone, J. Geophys. Res., 97, 4809-4822.

Ghiorso, M. S. (1997), Thermodynamic models of igneous preocesses, Ann. Rev. Earth Planet. Sci., 25, 221-241.

Ghiorso, M. S., and I. S. E. Carmichael (1980), Regular solution model for met-aluminous silicate liquids - applications to geothermometry, immiscibility, and the source regions of basic magmas, Contib. Mineral. Petrol., 71, 323-342.

Goes, S., F. Cammarano, and U. Hansen (2004), Synthetic seismic signature of thermal mantle plumes, Earth Planet. Sci. Lett., 218, 403-419.

Grand, S. P., R. van der Hilst, and S. Widiyantoro (1997), Global seismic tomography a snapshot of convection in the earth, GSA Today, 7(4), 1-7.

Hart, S. R., and A. Zindler (1989), Constraints on the nature and development of chemical heterogeneities in the mantle, in: Mantle Convection, W.R. Peltier, Gordon and Breach Science Publishers, New York. 
Hirose, K., Y. Fei, Y. Ma, and H.-K. Mao (1999), The fate of subducted basaltic crust in the earth's lower mantle, Nature, 397, 53-56.

Hirose, K., Y. Fei, S. Ono, T. Yagi, and K. i. Funakoshi (2001), In situ measurements of phase transformation boundary in $\mathrm{Mg}_{3} \mathrm{Al}_{2} \mathrm{Si}_{3} \mathrm{O}_{12}$, Earth Planet. Sci. Lett., 184, 567-573.

Irifune, T., and M. Isshiki (1998), Iron partitioning in a pyrolite mantle and the nature of the 410-km seismic discontinuity, Nature, 392, 702-705.

Irifune, T., and A. Ringwood (1993), Phase transformations in subducted oceanic crust and buoyancy relationships at depths of 600-800 km in the mantle, Earth Planet. Sci. Lett., 117, 101-110.

Irifune, T., and A. E. Ringwood (1987), Phase transformations in a harzburgite composition to 26 GPa: implications for dynamical behaviour of the subducting slab, Earth Planet. Sci. Lett., 86, 365-376.

Irifune, T., T. Koizumi, and J. Ando (1996), An experimental study of the garnet-perovskite transformation in the system $\mathrm{MgSiO}_{3}-\mathrm{Mg}_{3} \mathrm{Al}_{2} \mathrm{Si}_{3} \mathrm{O}_{12}$, Phys. Earth Planet. Inter., 96, 147-157.

Ita, J., and L. Stixrude (1992), Petrology, elasticity, and composition of the mantle transition zone, J. Geophys. Res., 97(B5), 9849-6866.

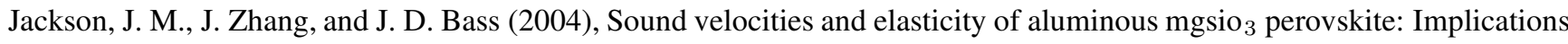
for aluminum heterogeneity in earth's lower mantle, Geophys. Res. J.

Karason, H., and R. van der Hilst (2000), Constraints on mantle convection from seismic tomography, in: The History and Dynamics of Global Plate Motion, vol. 121, 277-288 pp., Richards, M.R., R. Gordon, and R.D. van der Hilst, Geophysical Monograph AGU, Washington, D.C.

Kerschhofer, L., D. C. Rubie, T. G. Sharp, J. D. C. McConnell, and C. Dupas-Bruzek (2000), Kinetics of intracrystalline olivine-ringwoodite transformation, Phys. Earth Planet. Inter, 121, 59-76.

Kirby, S. H., S. Stein, E. A. Okal, and D. Rubie (1996), Metastable mantle phase transformations and deep earthquakes in subducting oceanic lithosphere, Rev. Geophys., 34, 261-306.

Kubo, A., and M. Akaogi (2000), Post-garnet transitions in the system $\mathrm{Mg}_{4} \mathrm{Si}_{4} \mathrm{O}_{12}-\mathrm{Mg}_{3} \mathrm{Al}_{2} \mathrm{Si}_{3} \mathrm{O}_{12}$ up to 28 GPa: phase relations of garnet, ilmenite and perovskite, Phys. Earth Planet. Inter., 121, 85-102.

Kung, J., B. Li, D. J. Weidner, J. Zhang, and R. C. Liebermann (2002), Elasticity of $\left(\mathrm{Mg}_{0.83} \mathrm{Fe}_{0.17}\right)$ o ferropericlase at high pressure: ultrasonic measurements in conjunction with X-radiation techniques, Earth Planet. Sci. Lett., 203, 557-566.

Kuskov, O. L., and A. B. Panferov (1991), Phase-diagrams of the $\mathrm{FeO}-\mathrm{Mg0}-\mathrm{SiO}_{2}$ system and the structure of the mantle discontinuities, Phys. Chem. Miner., 17, 642-653.

Lithgow-Bertelloni, C., M. A. Richards, Y. Ricard, R. J. O’Connell, and D. C. Engebretson (1993), Toroidal-poloidal partitioning of plate motions since $120 \mathrm{ma}$, Geophys. Res. Lett., 20, 375-378.

Masters, G., G. Laske, H. Bolton, and A. Dziewonski (200), The relative behavior of shear velocity, bulk sound speed, and compressional velocity in the mantle: Implications for chemical and thermal structure, in: Earth's Deep Interior, vol. 117, S. Karato, A. M. Forte, R. C. Liebermann, G. Masters and L. Stixrude, Geophysical Monograph AGU, Washington, D.C.

Matas, J. (1999), Modélisation thermochimique des propriétés de solides à hautes températures et hautes pressions. applications géophysiques., Ph.D. thesis, Ecole Normale Supérieure de Lyon, France.

Matas, J., P. Gillet, Y. Ricard, and I. Martinez (2000a), Thermodynamic properties of carbonates at high pressures from vibrational modelling, Eur. J. Mineral., 12, 703-720.

Matas, J., Y. Ricard, L. Lemelle, and F. Guyot (2000b), An improved thermodynamic model of metal-olivine-pyroxene stability domains, Contrib. Mineral. Petrol., 140, 73-83.

Mattern, E., J. Matas, Y. Ricard, and J. Bass (2005), Lower mantle composition and temperature from mineral physics and thermodynamic modelling, Geophys. J. Inter., in press.

Mosenfelder, J. L., J. A. D. Connolly, D. C. Rubie, and M. Liu (2000), Strength of (mg,fe)2sio4 wadsleyite determined by relaxation of transformation stress, Phys. Earth Planet. Inter., 120, 63-78.

Murakami, T., K. Hirose, K. Kawamura, N. Sata, and Y. Ohishi (2004), Post-perovskite phase transition in $\mathrm{MgSiO}_{3}$, Science, 304, 855-858.

Ono, S., E. Ito, and T. Katsura (2001), Mineralogy of subducted basaltic crust (MORB) from 25 to 37 gpa and chemical heterogeneity of the lower mantle, Earth Planet. Sci. Lett., 190, 57-63.

Perrillat, J. P., A. Ricolleau, I. Daniel, G. Fiquet, M. Mezouar, and H. Cardon (2004), Phase transformations of MORB in the lower mantle, Lithos, 73(1-2 Suppl. 1), S87-S87.

Ricard, Y., and N. Coltice (2004), Geophysical and geochemical models of mantle convection: Successes and future challenges, The state of the planet: Frontiers and challenges in geophysics, vol. 150, 59-68 pp., Geophys. Monogr. Ser.

Ricard, Y., M. Richards, C. Lithgow-Bertelloni, and Y. L. Stunff (1993), A geodynamic model of mantle density heterogeneity, J. Geophys. Res., 98, 21,895-21,909. 
Richards, M. (1991), Hotspots and the case for a high viscosity lower mantle, in Glacial Isostasy, Sea-Level and Mantle Rheology, R. Sabadini et al., eds, 571-587 pp., Kluwer Academic Publishers, Dordrecht.

Richards, M. A., and D. C. Engebretson (1992), Large-scale mantle convection and the history of subduction, Nature, 355, 437-440.

Ricolleau, A., G. Fiquet, J. Perillat, I. Daniel, N. Menguy, H. Cardon, A. Addad, C. Vanni, and N. Guignot (2004), The fate of subducted basaltic crust in the earth's lower mantle: an experimental petrological study, in Eos Trans. AGU, Fall Meet. Suppl, vol. 85(47), abstract U33B-02.

Ringwood, A. (1982), Phase transformations and differentiation in subducted lithosphere: implications for mantle dynamics, basalt petrogenesis, and crustal evolution, J. Geol., 90(6), 611-642.

Ringwood, A. E. (1991), Phase transformations and their bearing on the constitution and dynamics of the mantle, Geochim. Cosmochim. Acta, 55, 2083-2110.

Ringwood, A. E., and T. Irifune (1988), Nature of the 650-km seismic discontinuity: implications for mantle dynamics and differentiation, Nature, 331, 131-136.

Ritsema, J., and H. J. van Heijst (2000), Seismic imaging of structural heterogeneity in earth's mantle: Evidence for largescale mantle flow, Sci. Progr., 83, 243-259.

Saxena, S., N. Chatterjee, Y. Fei, and G. Shen (1993), Thermodynamic Data on Oxides and Silicates, Thermodynamic Data on Oxides and Silicates. Springer-Verlag.

Saxena, S. K. (1996), Earth mineralogical model: Gibbs free energy minimization computation in the system mgo-feo-sio 2 , Geochim. Cosmochim. Acta, 60, 2379-2395.

Saxena, S. K., and G. Eriksson (1983), Theoritical computation of mineral assemblages in pyrolite and lherzolite, J. Petrol., 24, 538-555.

Sinogeikin, S. V., and J. D. Bass (2002), Elasticity of pyrope and majorite-pyrope solid solutions to high temperatures, Earth Planet. Sci. Lett., 203.

Smith, W. R., and R. Missen (1991), Chemical reaction equilibrium analysis: theory and algorithms, Krieger Publishing Company, Malabar, Florida.

Sobolev, S. V., and A. Y. Babeyko (1994), Modeling of mineralogical composition, density and elastic-wave veleocities in anhydous magmatic rocks, Surv. Geophys., 15, 515-544.

Spear, F. S. (1995), Metamorphic phase equilibria and pressure-temperature-time paths, 1-799 pp., Mineralogical Society of America, Monograph.

Stacey, F. D. (1992), Physics of the Earth, 3rd edition, Brookfield press.

Stixrude, L. (1997), Structure and sharpness of phase transitions and mantle discontinuities, J. Geophys. Res., 102, 14,83514,852 .

Tackley, P. (2000), Mantle convection and plate tectonics: toward an integrated physical and chemical theory, Science, 288, 2002-2007.

Takafuji, N., T. Yagi, N. Miyajima, and T. Sumita (2002), Study on $\mathrm{Al}_{2} \mathrm{O}_{3}$ content and phase stability of aluminous-CaSiO 3 perovskite at high pressure and temperature, Phys. Chem. Min., 29, 532-537.

Trampert, J., F. Deschamp, J. Resovsky, and D. Yuen (2004), Probabilistic tomography maps chemical heterogeneities throughout the lower mantle, Science, 306, 853-856.

Turcotte, D. L., and G. Schubert (1982), Geodynamics: applications of continuum physics to geological problems, 1-450 pp., Wiley, New York.

Vacher, P., A. Mocquet, and C. Sotin (1998), Computation of seismic profiles from mineral physics: the importance of the non-olivine components for explaining the $660 \mathrm{~km}$ depth discontinuity, Phys. Earth Planet. Inter., 106, 275-298.

van der Voo, R., W. Spakman, and H. Bijwaard (1999), Mesozoic subducted slabs under siberia, Nature, 397, $246-249$.

van Keken, P. E., and C. J. Ballentine (1998), Whole-mantle versus layered convection and the role of a high-viscosity lower mantle in terrestrial volatile evolution, Earth Planet. Sci. Lett., 156, 19-32.

Watt, J. P., G. F. Davies, and R. J. O'Connell (1976), Elastic properties of composite-materials, Rev. Geophys., 14, 541-563.

Wood, B. J. (1987), Thermodynamics of multicomponent systems containing several solid-solutions, Rev. Mineral., 17, 7195.

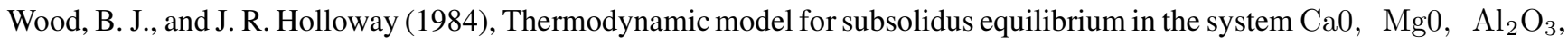
Geochim. Cosmochim. Acta, 48, 159-176.

Y. Ricard, Laboratoire des Sciences de la Terre, UMR CNRS 5570, Université Lyon 1, boulevard du 11 novembre, Villeurbanne, France. (ricard@ens-lyon.fr) 
E. Mattern, Laboratoire des Sciences de la Terre, UMR CNRS 5570, Ecole Normale Supérieure de Lyon, 46 allée d'Italie, F-69364 Lyon, Cedex 07, France. (emattern@ens-lyon.fr)

J. Matas, Laboratoire des Sciences de la Terre, UMR CNRS 5570, Ecole Normale Supérieure de Lyon, 46 allée d'Italie, F-69364 Lyon, Cedex 07, France. (jmatas@ens-lyon.fr)

This preprint was prepared with AGU's $\mathrm{LAT}_{\mathrm{E}} \mathrm{X}$ macros v4, with the extension package 'AGU++' by P. W. Daly, version 1.6b from 1999/08/19. 